MOLECULAR CANCER

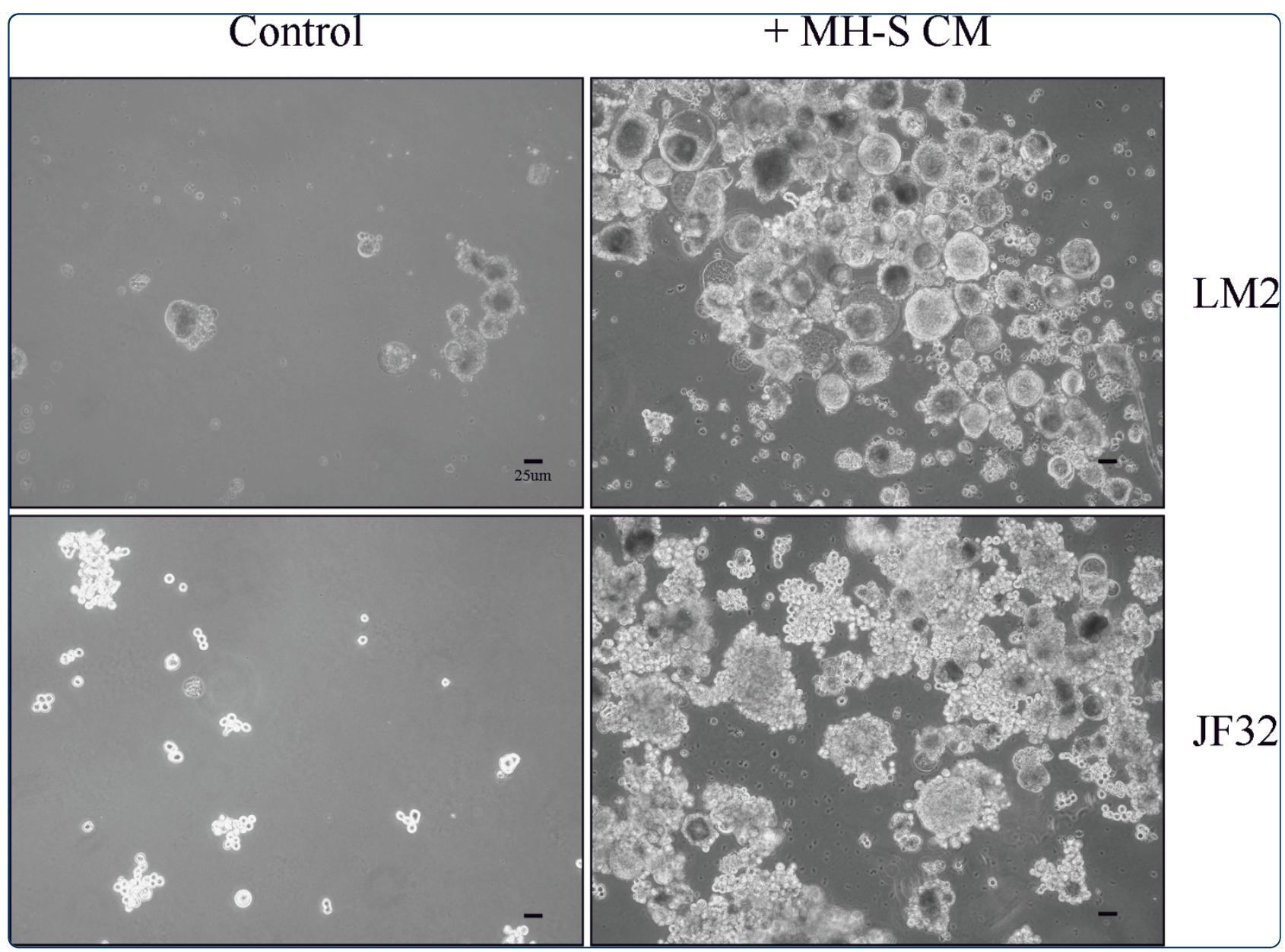

Stimulation of neoplastic mouse lung cell proliferation by alveolar macrophage-derived, insulin-like growth factor-1 can be blocked by inhibiting MEK and PI3K activation

Fritz et al. 


\title{
Stimulation of neoplastic mouse lung cell proliferation by alveolar macrophage-derived, insulin-like growth factor-1 can be blocked by inhibiting MEK and PI3K activation
}

\author{
Jason M Fritz, Lori D Dwyer-Nield ${ }^{*}$ and Alvin M Malkinson
}

\begin{abstract}
Background: Worldwide, lung cancer kills more people than breast, colon and prostate cancer combined. Alterations in macrophage number and function during lung tumorigenesis suggest that these immune effector cells stimulate lung cancer growth. Evidence from cancer models in other tissues suggests that cancer cells actively recruit growth factor-producing macrophages through a reciprocal signaling pathway. While the levels of lung macrophages increase during tumor progression in mouse models of lung cancer, and high pulmonary macrophage content correlates with a poor prognosis in human non-small cell lung cancer, the specific role of alveolar macrophages in lung tumorigenesis is not clear.
\end{abstract}

Methods: After culturing either an immortalized lung macrophage cell line or primary murine alveolar macrophages from naïve and lung-tumor bearing mice with primary tumor isolates and immortalized cell lines, the effects on epithelial proliferation and cellular kinase activation were determined. Insulin-like growth factor-1 (IGF-1) was quantified by ELISA, and macrophage conditioned media IGF-1 levels manipulated by IL-4 treatment, immuno-depletion and siRNA transfection.

Results: Primary macrophages from both naïve and lung-tumor bearing mice stimulated epithelial cell proliferation. The lungs of tumor-bearing mice contained 3.5-times more IGF-1 than naive littermates, and media conditioned by freshly isolated tumor-educated macrophages contained more IGF-1 than media conditioned by naïve macrophages; IL-4 stimulated IGF-1 production by both macrophage subsets. The ability of macrophage conditioned media to stimulate neoplastic proliferation correlated with media IGF-1 levels, and recombinant IGF-1 alone was sufficient to induce epithelial proliferation in all cell lines evaluated. Macrophage-conditioned media and IGF-1 stimulated lung tumor cell growth in an additive manner, while EGF had no effect. Macrophage-derived factors increased p-Erk1/2, p-Akt and cyclin D1 levels in neoplastic cells, and the combined inhibition of both MEK and PI3K ablated macrophage-mediated increases in epithelial growth.

Conclusions: Macrophages produce IGF-1 which directly stimulates neoplastic proliferation through Erk and Akt activation. This observation suggests that combining macrophage ablation therapy with IGF-1R, MEK and/or PI3K inhibition could improve therapeutic response in human lung cancer. Exploring macrophage-based intervention could be a fruitful avenue for future research.

Keywords: Lung cancer, macrophages, proliferation, IGF-1, cytokines

\footnotetext{
* Correspondence: Lori.Nield@ucdenver.edu

Department of Pharmaceutical Sciences, Skagg School of Pharmacy and

Pharmaceutical Sciences, University of Colorado Anschutz Medical Campus,

12850 E. Montview Blvd, C-238 V20-4460, Aurora, CO. 80045, USA
} 


\section{Background}

Lung cancer is a worldwide epidemic. In 2009, nearly 160,000 people died from lung cancer in the U.S. alone. The five-year survival rate slightly increased from $13 \%$ to $15 \%$ over the last 25 years, mainly due to limited early cancer detection and minor improvements in therapy [1]. Non-small cell lung cancer (NSCLC) is the most common form of the disease, and adenocarcinoma (AC) of the distal lung the most frequently diagnosed subtype [2]. Persistent lung inflammation due to cigarette smoke and related pulmonary comorbidities such as chronic obstructive pulmonary disease increases the lifetime risk of developing lung cancer [3], which can be partially alleviated by long-term anti-inflammatory drug therapy $[4,5]$. Therefore, delineating the causal relationship between inflammation and lung carcinogenesis may lead to earlier diagnosis and more effective treatment.

To understand how chronic lung inflammation promotes the growth of lung cancer, it is important to examine communication between pulmonary epithelial cells and inflammatory effector cells such as alveolar macrophages. Macrophages are the most abundant type of immune cell in a healthy lung [6], and alveolar macrophage numbers increase dramatically as chronic diseases like NSCLC progress [7-9]. Macrophages infiltrate most solid cancers, including NSCLC, and lung cancer patients display an inverse relationship between macrophage infiltration and survival $[7,9]$. Local environmental stimuli modulate macrophage function, a process referred to as macrophage activation or polarization. Classical macrophage activation arises in response to tissue damage signals, whereas alternative activation is associated with wound healing and cancer progression $[10,11]$. In experimental mouse models of NSCLC, alveolar macrophages become alternatively activated within weeks of lung tumor initiation [6]. Chemical depletion of macrophages delays lung tumorigenesis, while chemically-induced chronic inflammation greatly increases lung macrophage content and stimulates lung tumor growth [12].

Although the mechanisms by which recruited macrophages contribute to lung $\mathrm{AC}$ growth and progression have not been delineated, the reciprocal growth factor interaction between macrophages and breast cancer cells suggests one possibility $[13,14]$. In mouse models of invasive breast cancer, macrophage-secreted epidermal growth factor (EGF) stimulates growth and migration of mammary tumor cells, which in turn secrete colony stimulating factor- 1 (CSF-1) to recruit additional macrophages to the tumor site [13]. This reciprocal growth factor signaling cascade can induce the migration of neoplastic cells from the primary breast tumor site into systemic circulation, dramatically increasing the potential for metastatic colonization [15]. Unlike breast cancer, little is known regarding the contribution of macrophage-derived growth factors to lung cancer growth.

Compared to macrophages in other tissues, the alveolar macrophage is fairly unique due to the monocyte differentiation cytokines present in the lung microenvironment. Specifically, granulocyte-monocyte colony stimulating factor (GM-CSF) is highly expressed while local concentrations of CSF-1 are typically low. High levels of GM-CSF induce the differentiation of blood monocytes into dendritic-like cells, instead of the more traditional macrophage-like fate directed by CSF-1 [9]. Consistent with these observations, alveolar macrophages more closely resemble immature dendritic cells than do macrophages isolated from other tissues [16]. Because of these distinct differences in morphology and function, pulmonary macrophages may stimulate lung cancer proliferation by providing growth factors different than those described in breast and ovarian cancer. While cultured lung AC cells produce several macrophage chemoattractants, including IL- $1 \beta$ and GM-CSF $[17,18]$, there are few reports of any reciprocal growth factor exchange between primary alveolar macrophages and NSCLC [18]. Although the specific factors have not been clearly identified, tumor growth may be stimulated through common downstream signaling mechanisms such as increased Erk1/2 activity, as Erk1/2 is hyperactivated in NSCLC $[19,20]$. Thus, in addition to identifying lung macrophage-derived tumor growth factors, targeting signaling pathways common to neoplastic growth may also be therapeutically beneficial.

Nearly $25 \%$ of NSCLCs contain activating mutations in KRAS, resulting in growth stimulation through increased Erk1/2 and Akt activities [21,22]. Krasmediated activation of extracellular-regulated kinase kinase (MEK) and phosphoinositide-3 kinase (PI3K) directly increases proliferation and cell survival through transcriptional regulation, increased cell cycle progression, and inhibition of pro-apoptotic factors [20,23]. Although Kras signals through multiple downstream effectors, experimental studies have shown that lung tumors containing mutated Kras are clearly dependent on cellular kinases such as Erk1/2 and Akt for continued growth and survival [24]. Mutations in Kras are sufficient to initiate lung tumorigenesis [25], and chronically high lung macrophage content greatly accelerates the growth and progression of this disease [5,12]. Many growth factors stimulate Erk1/2 and Akt activity in healthy tissues; among these, insulin-like growth factor 1 (IGF-1) is associated with neoplastic growth and expansion $[26,27]$. In mouse lungs, IGF-1 was originally identified as an alveolar macrophage-derived growth 
factor $[28,29]$, and increased macrophage IGF-1 production has been observed in models of environmental lung injury [30]. IGF-1 receptor inhibition is currently under intensive clinical investigation, and early reports show therapeutic promise in some NSCLC patients [12,27]. Therefore, IGF-1 could be one candidate by which lung macrophages accelerate the growth of lung tumors.

We sought to determine if chronic inflammation drives lung tumorigenesis, in part, by recruiting and polarizing alveolar macrophages, which in turn produce IGF-1 that directly stimulates neoplastic growth. Since both healthy and tumor-bearing lungs contain dozens of unique resident and infiltrating cell types [31], we cocultured primary and immortalized mouse lung cells with macrophages, and demonstrated increased epithelial proliferation after exposure to macrophages in a simplified in vitro system. Such macrophage co-culture stimulated Erk1/2 and Akt activation, increased cyclin D1 expression, and enhanced the proliferation of neoplastic lung cells; the inhibition of both MEK and PI3K could block this macrophage-augmented tumor cell growth. IGF-1 was detected in lung lavage fluid and macrophage conditioned media, and was significantly elevated in tumor-bearing lungs and tumor-educated macrophage-conditioned media. Our findings demonstrate that macrophages recruited to the chronically inflamed lung have an enhanced ability to directly augment neoplastic growth, suggesting that specifically targeting tumor-associated macrophages, in addition to macrophage-derived growth factors, may be beneficial for future cancer therapy.

\section{Results}

Macrophage conditioned media profoundly stimulates the anchorage-independent growth of lung tumor cells

Despite the correlation between lung macrophage content and lung tumor growth, the direct contribution of alveolar macrophages to lung tumor growth is unclear $[6,7,13]$. Media conditioned by an immortalized lung macrophage cell line, $\mathrm{MH}-\mathrm{S}$, has been previously reported to stimulate the migration of lung epithelial cells harboring Kras mutations [18]. To determine if $\mathrm{MH}-\mathrm{S}$ conditioned media directly stimulates neoplastic growth, we first evaluated neoplastic colony formation and cell number after long-term conditioned media exposure. In both the classic model of anchorage-independent neoplastic growth on soft agar (Figure 1A-C), and colonization on new ultra-low adherence, neutrally-charged plastic (Figure 1D-F), macrophage-conditioned media potently stimulated the proliferation of two Kras mutant lung tumor-derived cell lines (LM2 and JF32). Thus, macrophages secrete soluble molecules capable of greatly stimulating neoplastic colony formation and proliferation in vitro, which may shed light on the role of macrophage recruitment to lung cancer in vivo.

\section{Naïve and tumor-educated primary macrophage co- culture stimulates the proliferation of neoplastic and non- neoplastic pulmonary epithelial cells}

The relative ability of naïve vs. tumor-educated alveolar macrophages to directly stimulate lung epithelial cell proliferation not been reported. To determine if macrophages from the lungs of tumor-bearing mice could directly stimulate neoplastic cell growth in a co-culture system, neoplastic LM2 cells were co-cultured with bronchoalveolar lavage (BAL) macrophages (MØ) isolated from tumor-bearing mice, and monolayer growth was assessed (Figure 2A). Growth in standard tissue culture conditions measures proliferation per se, and not cell motility or the requirement for solid support, and permits the evaluation of non-neoplastic epithelial cells which do not proliferate in anchorage-independent systems. LM2 cell number significantly increased with BAL macrophage co-culture at 48 (2.3 vs. 4.1 -fold) and 72 hrs (3.5 vs. 7.5-fold) (Figure 2A). As 72 hrs of macrophage co-culture resulted in $\geq 2$-times more tumor cells, this time point was used in subsequent experiments. To determine if tumor-educated macrophages stimulated neoplastic growth more effectively than naïve, BAL macrophages from either naïve or tumorbearing mice were co-cultured with neoplastic LM2 (Figure 2B) and JF32 (Figure 2C) cells. LM2 growth was equally stimulated by both naïve and tumor-educated BAL macrophages, while the growth of JF32 cells was enhanced slightly upon co-culture with tumor-educated BAL macrophages (Figure $2 \mathrm{C}$ ). To determine if primary alveolar macrophages also stimulated the proliferation of non-tumor cells, the non-neoplastic E10 cell line was co-cultured with naïve and tumor-educated BAL macrophages. Both macrophage types increased E10 cell number 3.5-fold (Figure 2D) when maintained in serum-free conditions; only tumor-educated macrophages stimulated E10 proliferation when cultured in the presence of serum (Figure 2E). Both types of primary macrophages equally stimulated LM2 proliferation in the presence of serum, though the magnitude was reduced when compared to serum-free co-culture (data not shown).

To determine if $\mathrm{MH}-\mathrm{S}$ macrophages could recapitulate the effects of primary alveolar macrophages in this in vitro model, we co-cultured $\mathrm{MH}-\mathrm{S}$ macrophages with both neoplastic and non-neoplastic lung epithelial cells. $\mathrm{MH}-\mathrm{S}$ co-culture increased the growth rate of all pulmonary epithelial cell lines similar to co-culture with tumor-educated BAL macrophages (Figure 2B-E). These results indicate that primary lung macrophages produce diffusible signals which can augment the proliferation of both non-neoplastic and neoplastic cells in vitro. 


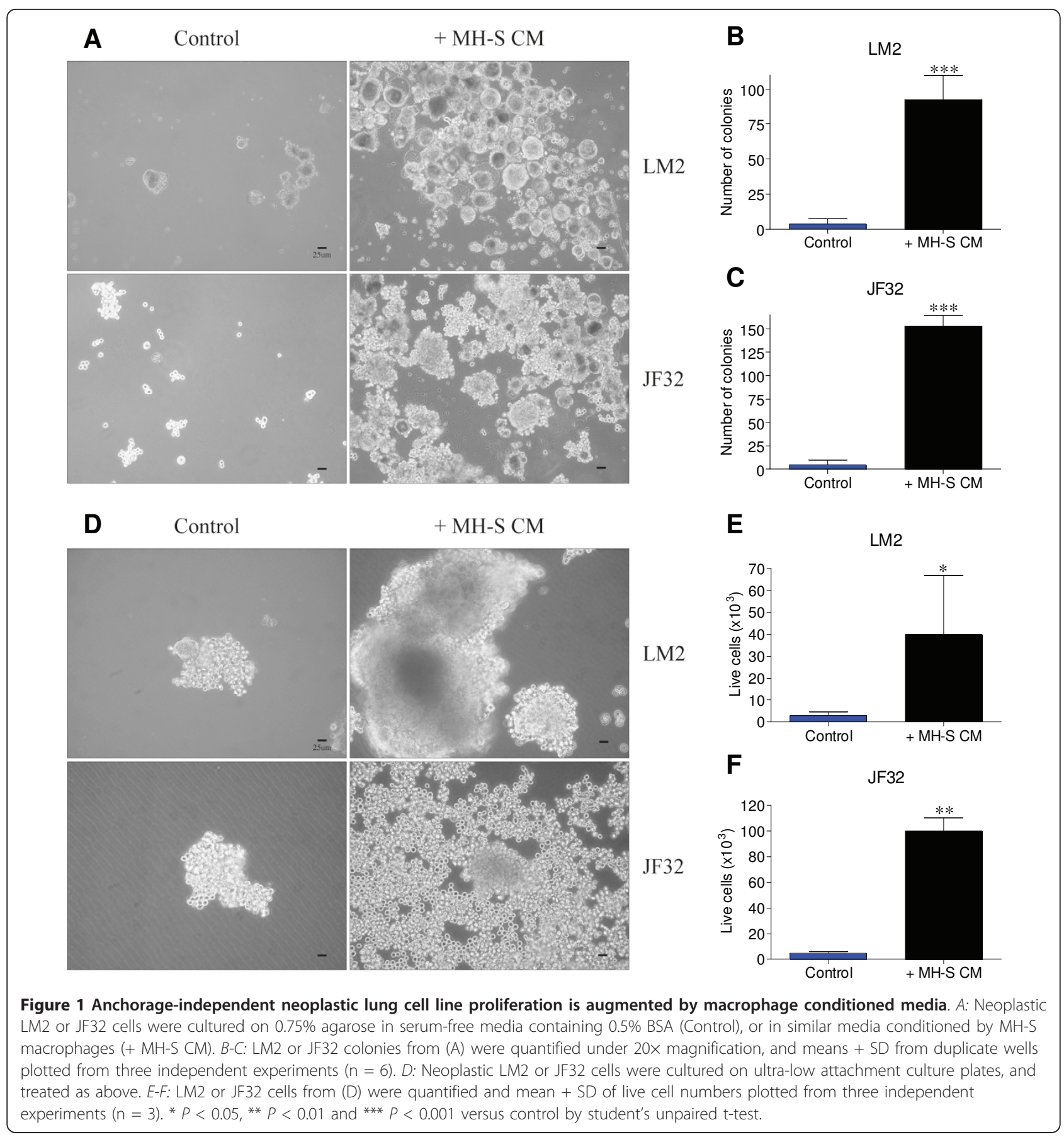

Further, we observed that in vivo tumor education of primary lung macrophages slightly enhances this ability to stimulate epithelial proliferation, an effect similar to co-culture with MH-S macrophages.

\section{Macrophage co-culture stimulates epithelial proliferation through kinase activation}

Since MH-S macrophages and tumor-educated primary macrophages stimulated epithelial proliferation to a similar degree, MH-S macrophages were used to elucidate the mechanisms of increased epithelial proliferation. Because Kras pathways are commonly hyper-activated in lung tumorigenesis [22,23], and the tumorigenic lines examined herein contain Kras mutations, activities of downstream mediators Erk and Akt were examined. Cytosolic Raf functionally links the Erk and Akt pathways; activated Akt can phosphorylate cRaf at S259, placing Erk regulation downstream of Akt activation [32,33]. 


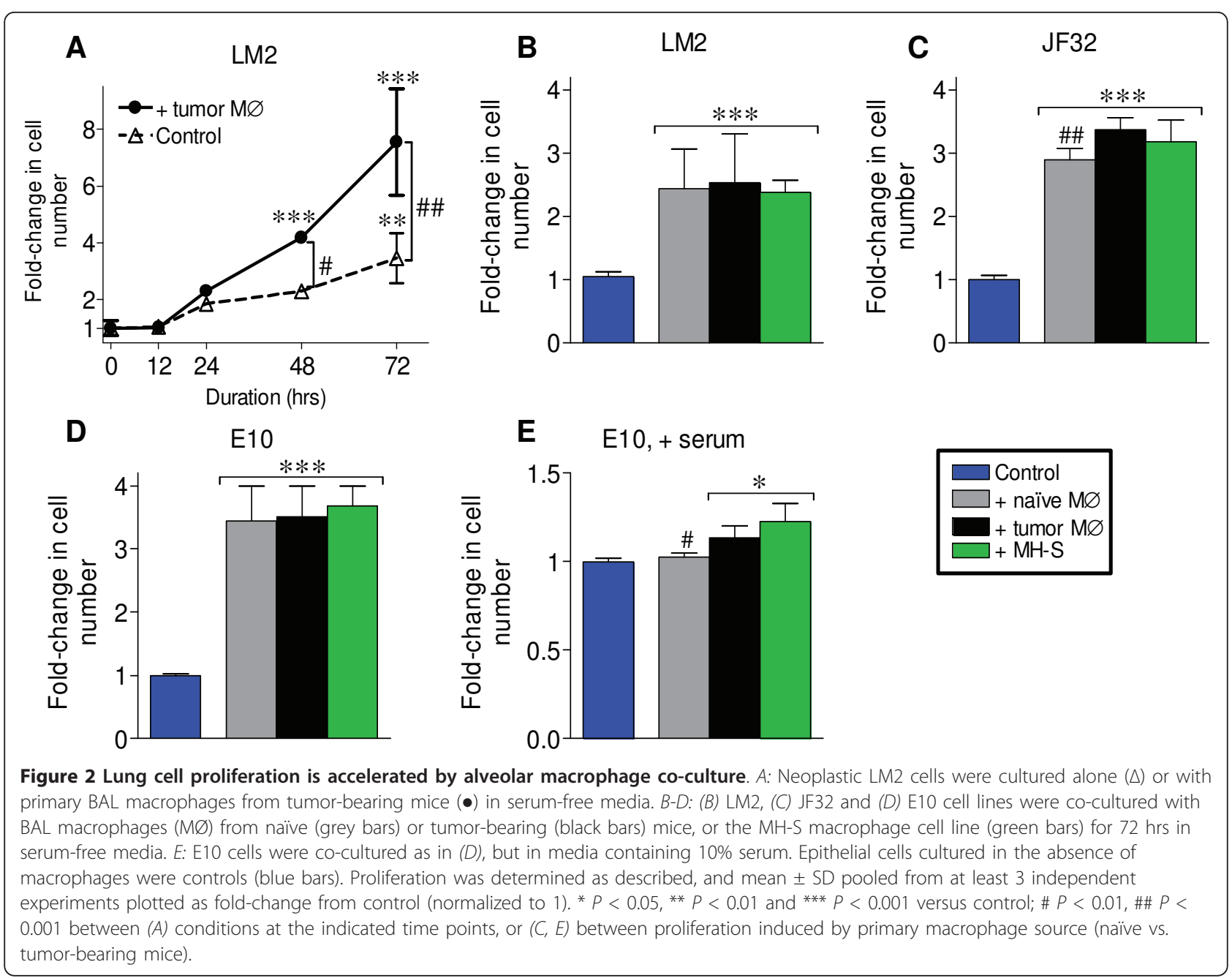

$\mathrm{MH}-\mathrm{S}$ co-culture stimulated cRaf phosphorylation at S259 in all three cell lines, resulting in significantly higher levels of p-cRaf (Figure 3A-C). The smaller ( 74 kDa) pcRaf isoform was most highly abundant and its phosphorylation significantly increased with macrophage coculture in the LM2 and E10 cells, but a larger $(\sim 100 \mathrm{kDa})$ isoform was heavily phosphorylated at the expense of the $74 \mathrm{kDa}$ isoform in neoplastic JF32 cells (Figure 3A). The $74 \mathrm{kDa}$ isoform was the most abundant in total cRaf immunoblots from all three cell lines.

$\mathrm{MH}-\mathrm{S}$ co-culture significantly increased the levels of active Erk1/2 (p-Erk) in LM2 and JF32 cells, as well as non-neoplastic E10 cells, when normalized either to total Erk (panErk) or $\beta$-actin levels (Figure 3A, D and 3E), which correlates with the observed increases in proliferation (Figure 2). E10 cells expressed lower basal p-Erk/ panErk vs. the neoplastic cell lines, consistent with previous observations [21]. Total Erk remained unchanged in both neoplastic cell lines, while macrophage co-culture caused Erk2 (42 kDa) to nearly disappear in the E10 cells, with little effect on Erk1 (Figure 3A, D and 3E). Activated
Akt (p-Akt) levels rose significantly in both neoplastic cell lines when normalized to either total Akt (panAkt) or $\beta$-actin, but macrophage co-culture caused both $\mathrm{p}$-Akt and panAkt levels to rise to similar extents in E10 cells (Figure 3A and 3F). When p-Akt was normalized to panAkt expression, there was no change in E10 cells with $\mathrm{MH}-\mathrm{S}$ co-culture (Figure 3F). Total Akt expression increased slightly in LM2 cells but decreased in JF32 cells (Figure 3A). When normalized to $\beta$-actin, p-Akt levels significantly increased upon $\mathrm{MH}-\mathrm{S}$ co-culture in all three cell lines (Figure 3A and 3G).

Increased p-S473 Akt content suggests increased enzymatic activity, which can be confirmed by enhanced phosphorylation of downstream substrates. To determine if macrophage co-culture increases Akt activity, we measured levels of p-GSK-3 $\beta$, a known target of Akt [32]. Consistent with the elevation in p-Akt, MH-S coculture significantly increased p-GSK-3 $\beta$ in both LM2 and E10 cells and trended towards an increase in JF32 cells (Figure $3 \mathrm{~A}$ and $3 \mathrm{H}$ ); panGSK-3 $\beta$ levels were unchanged (data not shown). Phospho-S259 cRaf is 


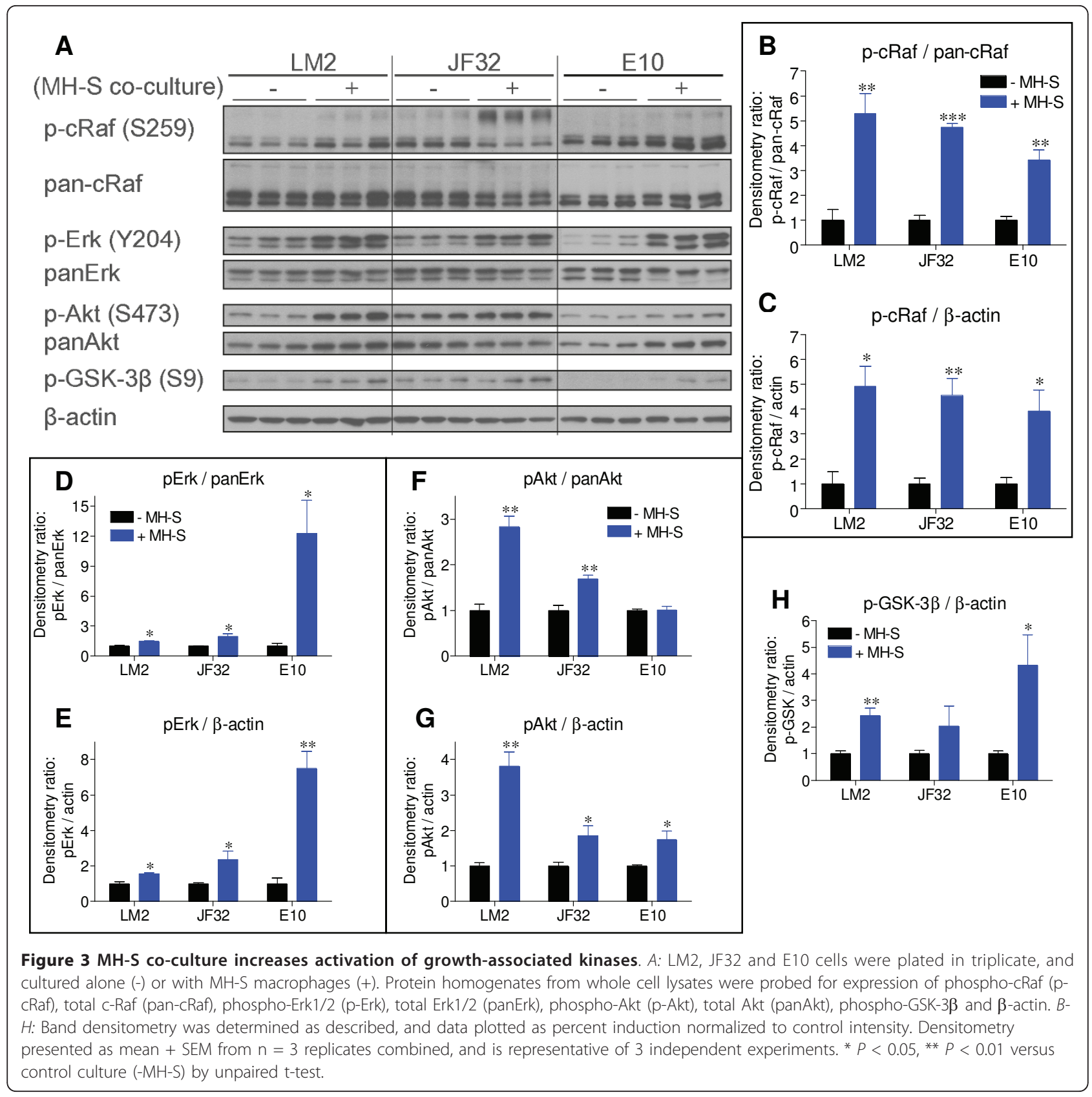

another measure of Akt activity, and p-cRaf levels increased in all three cell lines with macrophage co-culture (Figure 3A-C). Together, the observed increases in epithelial proliferation and the known roles for Erk and Akt in neoplastic lung cell division suggest that macrophage co-culture stimulates lung cell proliferation through increased Erk and Akt activity [34].

\section{Combined inhibition of MEK and PI3K abrogates macrophage stimulation of neoplastic growth}

Erk and Akt regulate both proliferation and resistance to apoptotic cell death, are more active in lung tumors than in normal tissue [21,35], and were activated with macrophage co-culture. Since combined MEK and PI3K inhibition slowed mutant Kras-driven lung tumor growth in vivo [25], we determined whether selective inhibition of MEK and PI3K affected macrophage-stimulated proliferation in these Kras mutant lung tumor cell lines. Selective inhibition of either MEK (by U0126) or PI3K (by LY294002) significantly decreased basal proliferation, and blocked growth stimulated by macrophage co-culture to different extents in LM2 and JF32 cells (Figure 4A and 4B, respectively). Only the combined inhibition of both kinases ablated the stimulatory effect 


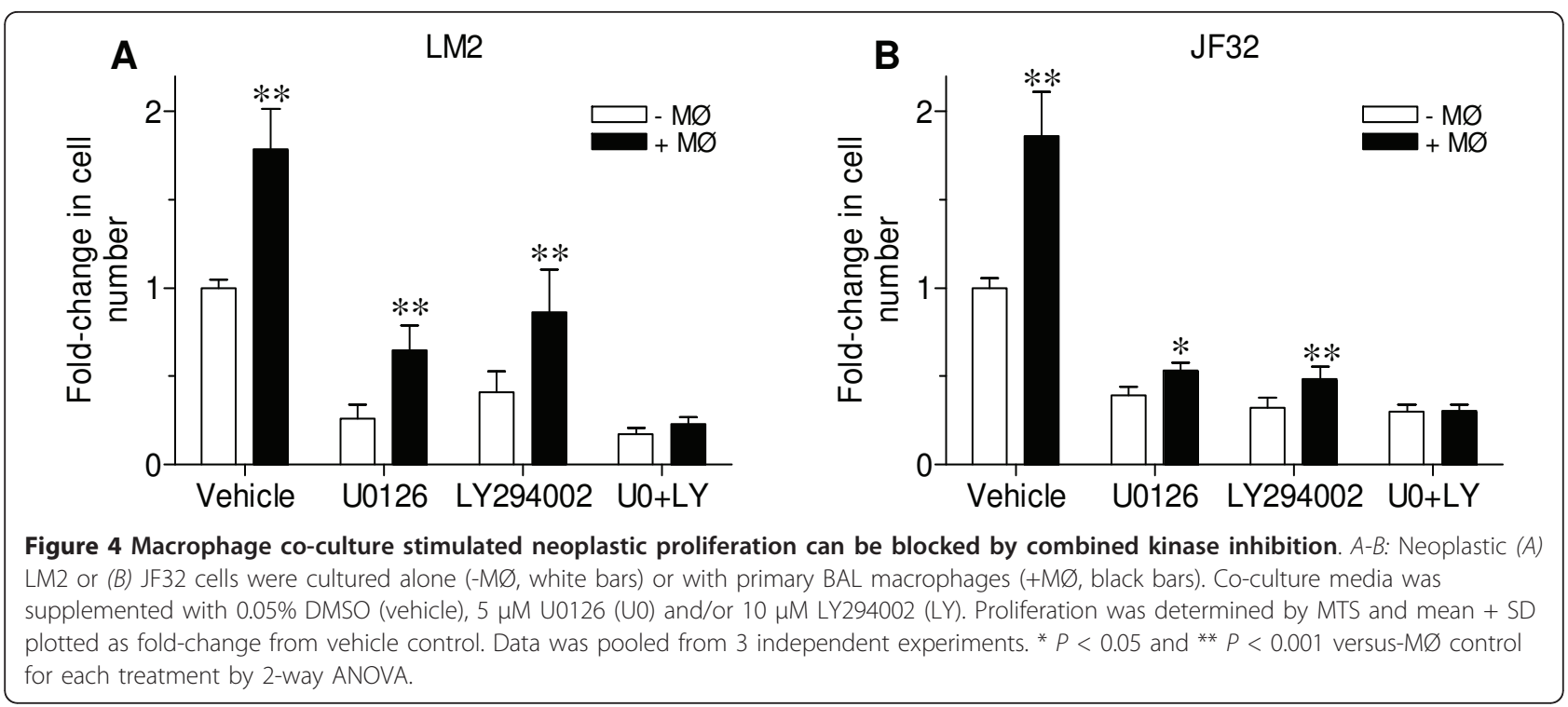

of macrophage co-culture on neoplastic proliferation (U0 + LY, Figure 4). Kinase inhibitors were applied at concentrations reported to be cytostatic and not cytotoxic [34,36,37], and none of these treatments significantly increased LM2 or JF32 cell death (data not shown). These results suggest that both the MEK and PI3K pathways must be blocked to effectively inhibit macrophage-stimulated neoplastic growth.

Macrophage conditioned media contains 3-10 kDa factors which stimulate neoplastic proliferation

Macrophages produce numerous cytokines, eicosanoids and other soluble factors depending upon tissue location and environmental stimuli $[4,18]$, any number of which could be responsible for the observed neoplastic growth stimulation described above. Media conditioned by primary BAL macrophages (MØCM) stimulated the proliferation of LM2 cells, albeit to a lesser extent than primary macrophage co-culture (Figure 5 "Total" vs. Figure 2B). When size-fractionated MØCM was added to LM2 cells, molecules between 3 and $10 \mathrm{kDa}$ stimulated LM2 growth to the greatest extent (Figure 5). Thus, factors of this size mediated the majority of MØCM effects on LM2 growth. Alveolar macrophages produce numerous growth factors in this size range, including IGF-1, GM-CSF and EGF $[11,18]$. To further narrow down the list of possible candidates, an in silico analysis was performed for each fraction size as described in Materials and Methods. The resulting data points were separately fit for each fraction size to the general equation $y=y_{0}+a\left(1-e^{-b x}\right)$ as described, with regression $r^{2}=0.997,0.842$ and 0.918 for the $>3,>10$ and $>30 \mathrm{kDa}$ fractions, respectively. From regression analysis, the responsible factor(s) appeared to be 7.23$10.8 \mathrm{kDa}$ in size, suggesting that growth factors such as
IGF-1 (7.5 kDa) may be responsible for the MØCM-stimulated neoplastic proliferation.

Macrophage-conditioned media IGF-1 levels correlate to effects on neoplastic proliferation

IGF-1 has a well-established role in the metastasis of cancer cells in vivo, as well as stimulating growth in vitro [27], and alveolar macrophages produce high levels

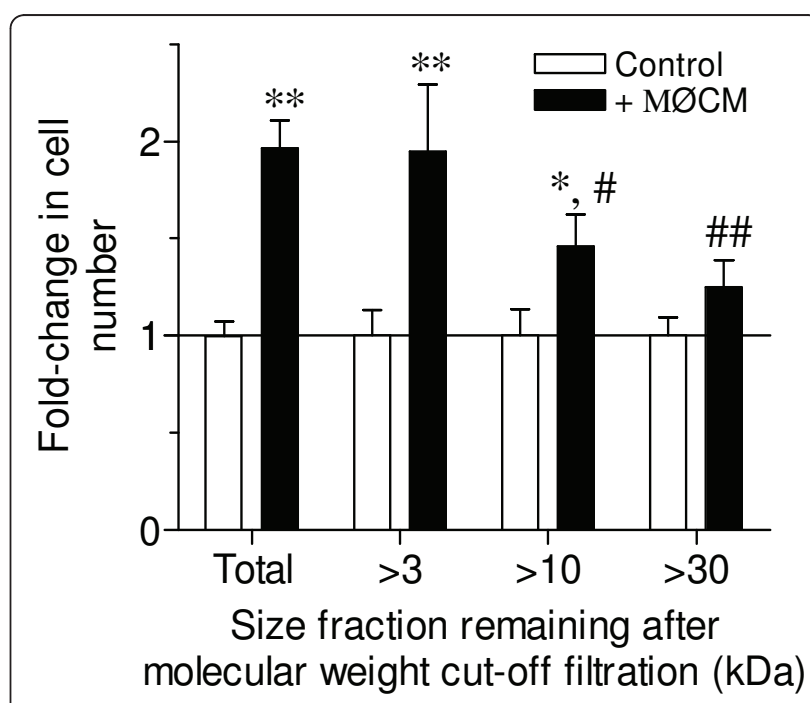

Figure 5 3-10 kDa molecules in MøCM stimulate epithelial proliferation. Neoplastic LM2 cells were cultured for 72 hrs after the addition of fresh media (Control, white bars) or MØCM (+MØCM, black bars), separated by size $(\mathrm{kDa})$ into the fractions indicated. Relative cell number was determined by MTS and mean + SD plotted as fold-change from control cultures, normalized for each size fraction. Data was pooled from $n=3$ independent experiments. ${ }^{*} P<0.01$ and ${ }^{*} P<0.001$ versus control within each fraction group, and \# $P<0.01$, \#\# $P<0.001$ versus total (unfractionated) MØCM by 2-way ANOVA. 
of IGF-1 in response to quartz dust-induced lung injury [30]. While alveolar macrophages are an important component of the chronic inflammatory milieu responsible for promoting lung tumorigenesis, IGF-1 has not been examined as a possible connection between macrophage recruitment and lung cancer progression. BALF from tumor-bearing lungs contained 3.5-times more IGF-1 than BALF from naïve mice, while EGF levels were unchanged (Figure 6A). Even after normalizing to total BALF protein levels, BALF IGF-1 was significantly higher in tumor-bearing animals than naïve controls $(1.81 \pm 0.33$ vs. $0.95 \pm 0.36 \mathrm{pg}$ IGF-1/ug BALF protein, respectively, $P<0.01$, mean $\pm \mathrm{SD}$ ), suggesting that more IGF-1 is produced in the lungs of tumor-bearing mice.

Measurement of IGF-1 levels in MØCM from primary naïve and tumor-educated BAL macrophages showed that tumor-educated macrophages produced significantly more IGF-1 than naïve macrophages (Figure 6B, grey bars). IL-4 potently stimulates alternative macrophage activation, and is more abundant in tumor-bearing lungs than naïve [38]. Alternative macrophage polarization is associated with tumorigenesis [6] and increased macrophage IGF-1 production [39]. Therefore,
IL-4 was added to wells containing primary naïve and tumor-educated BAL macrophages to determine if alternative activation could increase IGF-1 production in either macrophage group. Both naïve and tumor-educated macrophages produced significantly more IGF-1 after IL-4 treatment; tumor-educated macrophages more than doubled IGF-1 output compared to naïve samples (Figure 6B, green bars). MH-S macrophages produced 20-times more IGF-1 than either non-neoplastic or neoplastic lung cell lines, and all three cell lines produced only trace amounts $(<2 \mathrm{pg} / \mathrm{mL})$ of EGF (Figure $6 \mathrm{E})$.

In order to determine whether the growth effects of MØCM from samples generated in Figure 6B correlated with their IGF-1 content, MØCM was added to neoplastic LM2 cells. IL-4 stimulated naïve and tumor-educated MØCM significantly augmented LM2 proliferation (Figure $6 \mathrm{C}$, green bars), with IL-4 treated tumor-educated MØCM being the most potent. MØCM from untreated tumor-educated macrophages did not stimulate LM2 growth significantly more than untreated naïve MØCM (Figure 6C, grey bars), corresponding to previous co-culture results (Figure 2B). As the growth-stimulating ability of MØCM appeared to correlate to media IGF-1

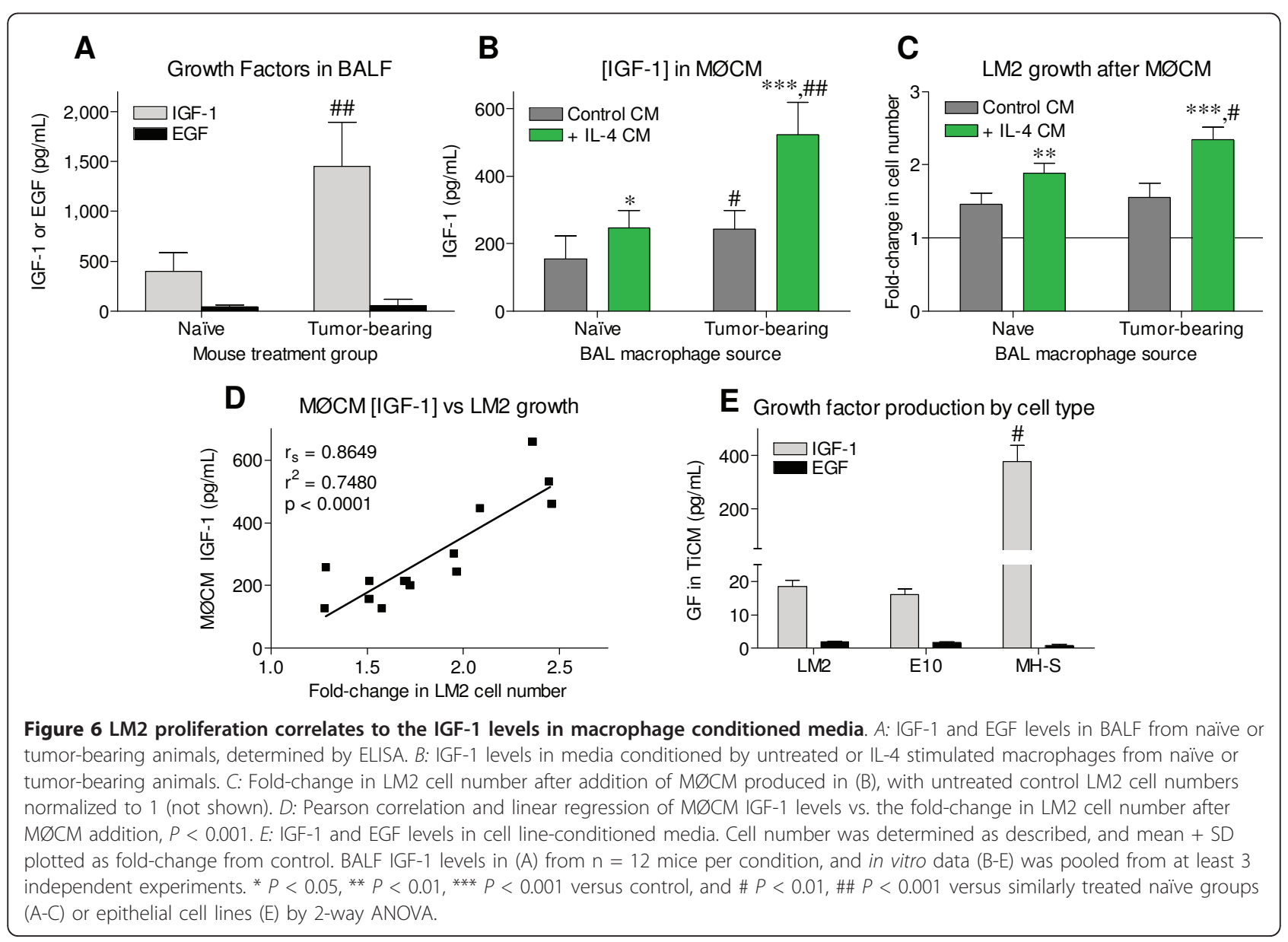


levels, the levels of IGF-1 present were plotted against the fold-change in LM2 cell number after MØCM addition (Figure 6D). The correlation between IGF-1 levels and neoplastic growth stimulation was highly significant ( $\mathrm{p}<0.001$ ), indicating that MØCM IGF-1 levels were directly related to the ability of $\mathrm{MØCM}$ to stimulate neoplastic proliferation.

\section{IGF-1 stimulates lung epithelial cell proliferation and is additive with $\mathrm{M \varnothing CM}$}

While IGF-1 levels correlated strongly with the ability of MØCM to stimulate neoplastic growth, IGF-1 induced proliferation of these non-neoplastic and neoplastic mouse lung cell lines has not been demonstrated. Recombinant mouse IGF-1 or MH-S macrophage-conditioned media was sufficient to stimulate the proliferation of neoplastic LM2, JF32 and E9 cells and non-neoplastic E10 cells (Figure 7A-D). The degree of growth stimulated by $50 \mathrm{ng} / \mathrm{mL}$ IGF- 1 was similar to that of MØCM in each line (Figure 7A-D). These results confirm that IGF-1 alone can stimulate the growth of long-established neoplastic and non-neoplastic cell lines, as well as cells isolated more recently from primary mouse lung tumors (JF32), consistent with previous reports on human cancer cell lines [27]. In order to determine any relevant role of EGFR in mediating macrophage-stimulated tumor cell proliferation in these cell lines, recombinant mouse EGF was added at $2 \mathrm{ng} / \mathrm{mL}$. This is roughly 500-times the reported $\mathrm{EC}_{50}$ for growth stimulation and 20-times higher than levels found in the BALF from tumor-bearing animals (Figure 6A). EGF had no significant effect on tumor cell proliferation when added alone, and did not significantly affect the ability of either IGF-1 or MØCM to stimulate neoplastic growth (Figure $7 E, F)$. This is not surprising in view of recent studies showing that EGFR inhibitors do not inhibit growth of lung cells with KRAS mutations [40].

As IGF-1 was sufficient to induce neoplastic proliferation, we determined whether the IGF-1 and MØCM growth effects were additive. A dose of $50 \mathrm{ng} / \mathrm{ml}$ IGF-1 stimulated neoplastic growth to a similar extent as MØСM (Figure 7A-D); $2 \mathrm{ng} / \mathrm{mL}$ IGF is the reported $\mathrm{EC}_{50}$ for IGF-1 stimulated proliferation in vitro as well as the concentration detected in the BALF of tumorbearing mice in vivo (Figure 6A). IGF-1 dose-dependently stimulated the proliferation of both LM2 and JF32 cells, and augmented the growth-stimulating effects of MØСМ when added in combination. To determine if IGF-1R signaling mediates both IGF-1 and MØCM stimulation, lung cancer cells were pre-treated with vehicle or $5 \mu \mathrm{M}$ NVP-AEW541 (- or + , respectively), and cell numbers determined as indicated. IGF-1 and MØCM each significantly increased cell numbers after 48 and 72 hrs, while pharmacological inhibition of IGF-1R signaling blocked IGF-1 and MØCM growth effects in both neoplastic lines (Figure 7G, H). Parallel comparison of MTS values indicated a highly significant correlation between live cell numbers and relative MTS scores $\left(\mathrm{r}^{2}=\right.$ 0.7912 and 0.8201 for LM2 and JF32, respectively, p < 0.0001 , data not shown). Furthermore, both IGF-1 and MØCM increased the fraction of $\mathrm{BrdU}^{+} \mathrm{LM} 2$ cells 12 $24 \mathrm{hrs}$ after treatment, corresponding with significantly increased cell numbers (data not shown). These observations suggest that IGF-1, but not EGF, plays a major role in macrophage stimulated neoplastic growth in vitro, consistent with the elevated IGF-1 levels observed in lung-tumor bearing animals in vivo.

\section{MØСM stimulation of neoplastic growth is diminished when IGF-1 content is decreased}

In order to determine if IGF-1 was a molecular mediator directly responsible for growth stimulated by МØСM, we decreased MØCM IGF-1 content through two independent avenues: immuno-depletion and siRNA interference. MØCM was concentrated to contain $\sim 3.5 \mathrm{ng} / \mathrm{mL}$ IGF-1, and then incubated with control IgG (Con IgG) or $\alpha$-IGF1 IgG coated resin, as described [39]. This procedure successfully decreased MØCM IGF-1 levels to $40-50 \%$ of control (Figure 8A). When this IGF-1 depleted media was added to LM2 and JF32 cells, growth stimulation was significantly decreased compared to untreated MØCM or IgG controls, which were identical (Figure 8B). In addition, $\mathrm{MH}-\mathrm{S}$ macrophage IGF-1 secretion was interrupted by transfection with scrambled control (scr siRNA) or siRNA constructs designed against mouse IGF-1 ( $\alpha$-IGF siRNA). One $\alpha$-IGF siRNA construct was more effective than the scr siRNA, and significantly decreased MØCM IGF-1 levels to $25 \%$ of control (Figure $8 \mathrm{C}$ ). The scr siRNA construct decreased macrophage IGF-1 secretion to a lesser extent (Figure 8C). Transfection reagents and conditions were chosen to minimize cellular toxicity, and media IGF1 content significantly decreased when normalized to MH-S viability (media IGF-1/MTS relative viability, data not shown). Neoplastic growth reflected the level of IGF-1 in the media conditioned by siRNA-treated macrophages, with all three groups differing significantly in JF32 cells (Figure 8D). While scr siRNA-treated media did not significantly lower LM2 cell growth, the correlation of media IGF-1 levels vs. LM2 proliferation was highly significant, as in JF32 cells (Figure 8D-F). Taken together, these experiments demonstrate that IGF-1 is responsible for the majority of neoplastic growth stimulated by MØСМ.

\section{Combined MEK and PI3K inhibition blocks IGF-1 and MØСM induced neoplastic proliferation by decreasing cyclin D1 expression}

IGF-1 stimulated neoplastic proliferation and mediated a significant portion of macrophage-induced tumor cell 


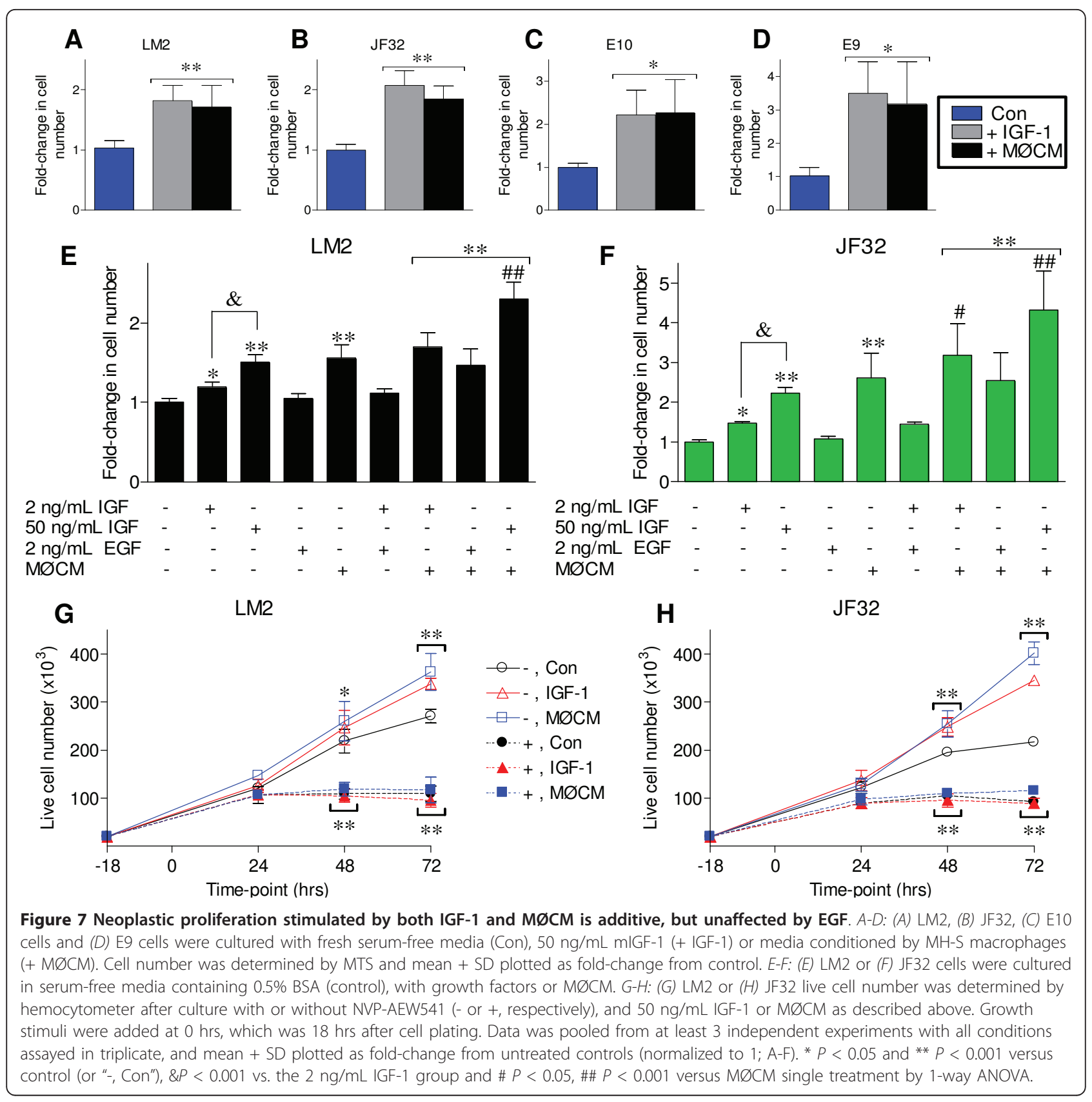

growth in culture. To determine if MØCM and/or IGF1 were similarly blocked by MEK and PI3K inhibition, LM2 and JF32 cells were treated with combinations of MEK and/or PI3K inhibitors, in the presence of IGF-1 or MØСМ. Analogous to previous results with macrophage co-culture, growth stimulated by either IGF-1 or MØСМ was blocked by combined inhibition of MEK and PI3K, to a greater extent than either pathway by itself (Figure 9A, B). Consistent with the proliferation results, cyclin D1 content (a biochemical correlate of lung cell proliferation [41]) was reduced by these inhibitors (Figure 9C-E).
MØCM induced early increases in cRaf, Akt and GSK$3 \beta$ phosphorylation, and Erk1/2 phosphorylation peaked at 24 hrs (Figure 9C, D). In both LM2 and JF32 cells, increased Akt phosphorylation corresponded to more phosphorylation of the Akt substrate, pGSK-3 $\beta$ (Figure 9H and 9I). Phospho-cRaf levels, another marker of Akt activity, also increased in concert with heightened increased Akt activity from 4-24 hrs; although p-cRaf abruptly dropped at $48 \mathrm{hrs}$, pAkt and pGSK-3 $\beta$ levels remained highly elevated (Figure 9F, $\mathrm{H}$ and 9I).

We observed reciprocal changes in the Erk and Akt pathways in response to their respective enzyme 
A

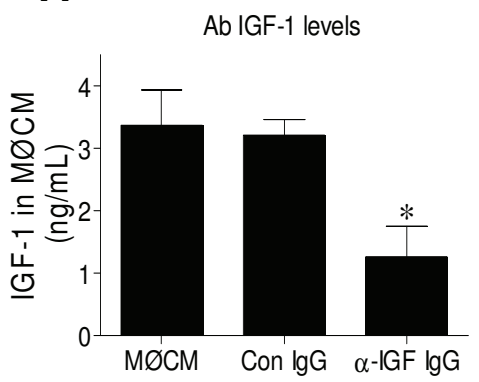

C

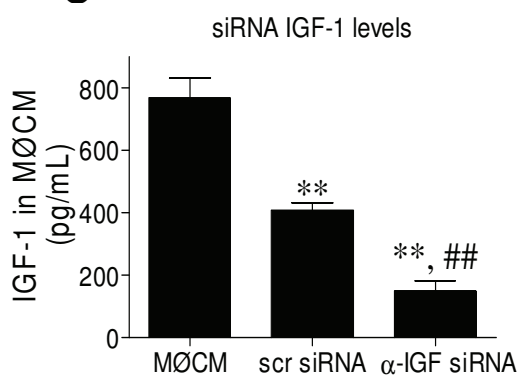

D
E

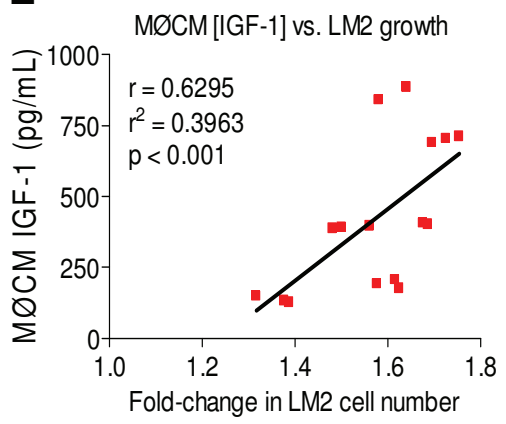

$\mathbf{F}$

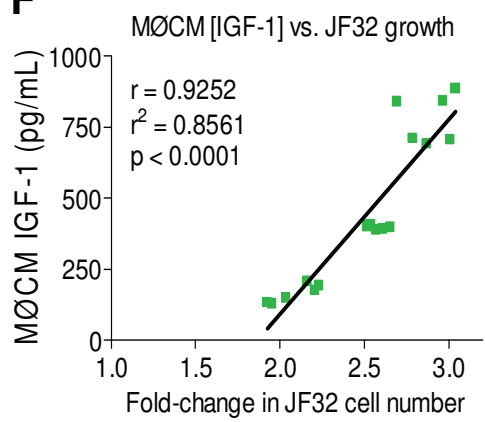

Fold-change in JF32 cell number
B

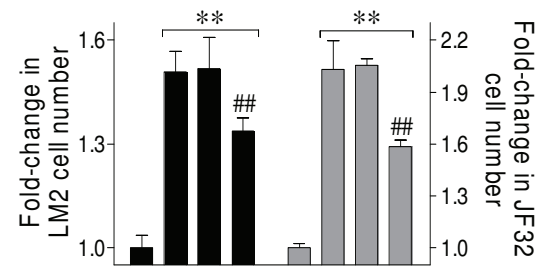

MøCM

Con $\lg \mathrm{G}-+++++$

$\alpha$-IGF IgG - - - + - - +

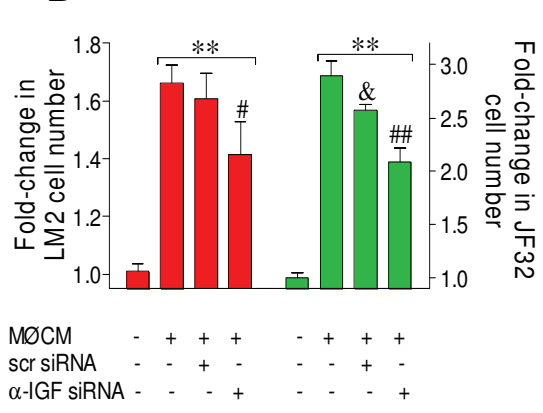

Figure 8 MøCM IGF-1 content regulates the proliferation of treated neoplastic cells. A-B: Macrophage-Conditioned media (M $\varnothing C M)$ was concentrated and immunoprecipitated against isotype control (Con IgG) or $\alpha$-mIGF-1 IgG antibodies ( $\alpha$-IGF IgG). (A) Media IGF-1 content was analyzed by ELISA, and (B) LM2 or JF32 cells were cultured in serum-free media with 0.5\% BSA, with or without the MØCM generated in (A). Relative growth was determined by MTS, and mean + SD plotted as fold-change from control, which was normalized to 1.0. Data was pooled from at least 3 independent experiments. ${ }^{*} P<0.01$ vs. Con IgG; ${ }^{* *} P<0.001$ versus untreated cells, and \#\# $P<0.001$ versus the Con IgG group by 1-way ANOVA. C-D: (C) IGF-1 concentration in media conditioned by macrophages pre-treated with scrambled control siRNA (scr siRNA) or $\alpha$ IGF-1 siRNA construct, vs. naïve MØCM, was determined by ELISA; (D) LM2 or JF32 cells were cultured and relative cell number determined as in (C). (C) ** $P<0.001$ vs. naïve M $\varnothing C M$ and \#\# $P<0.001$ versus the scr-siRNA by 1 -way ANOVA; $(D) * * P<0.001$ vs. untreated cells; \# $P<0.05$ and \#\# $P<0.001$ vs. the scr siRNA group; and \&P<0.001 vs. the M $\varnothing C M$ group by 1-way ANOVA. E-F: Pearson correlation and linear regression of MØCM IGF-1 levels from (C) vs. the fold-change in LM2 or JF32 cell number from (D) after M $\varnothing C M$ addition; (E) LM2 $P<0.001$ and (F) JF32 $P<$ 0.0001.

inhibitors. In LM2 cells, MEK inhibition (by U0126) suppressed early Erk1/2 phosphorylation while p-Akt levels increased. Conversely, PI3K inhibition (by LY294002) increased basal p-Erk1/2 levels at the expense of p-Akt ( $4 \mathrm{hrs}$ time point; Figure 9C). MEK inhibition raised p-Erk1/2 and total Erk1/2 levels at 24 and 48 hrs, while PI3K inhibition caused a compensatory increase in cellular p-Akt levels from 24-48 hrs. JF32 cell growth was also suppressed by each drug; although MEK inhibition did not affect p-Erk1/2 levels at $4 \mathrm{hrs}$, p-Erk1/2 levels decreased at $48 \mathrm{hrs}$ (Figure 9D). PI3K inhibition stimulated Erk1/2 phosphorylation from 4-24 hrs, and increased Akt phosphorylation throughout the treatment time-course (Figure 9G, H).

While each inhibitor decreased basal proliferation rates (Figure 9A, B), combinations of kinase inhibitors and MØCM increased cRaf, Erk1/2, Akt and GSK-3 $\beta$ phosphorylation in an additive manner, with the highest levels observed in cells treated with both kinase inhibitors and MØCM ("U+L +", Figure 9C-I). Total and p-
cRaf, p-Akt and p-GSK-3 $\beta$ were each significantly higher after 4-24 hrs of treatment in all groups receiving any combination of drug and MØCM, and p-Erk1/2 levels spiked after $24 \mathrm{hrs}$ of treatment (Figure 9F-I). Either inhibitor alone partially prevented the increase in cyclin D1 in cells treated with MØCM; cells receiving both inhibitors had the lowest cyclin D1 levels and were unresponsive to MØCM-induced growth (Figure 9E). Taken together, MØCM-induced neoplastic Akt and Erk1/2 phosphorylation was magnified several-fold by inhibitor treatment, dissociating kinase activity from proliferation in drug-treated cells; however, cyclin D1 levels were suppressed by either drug alone, which corresponded to decreased cell proliferation.

As with MØCM, IGF-1 stimulated both Akt and Erk1/2 activities. Kinase activation was greatest within $4 \mathrm{hrs}$ of treatment, and remained elevated $48 \mathrm{hrs}$ later, corresponding with increased cyclin D1 expression (Figure 10A-E). When treated with $2 \mathrm{ng} / \mathrm{mL}$ EGF, a concentration 1,000times higher than the amount of EGF in cell-conditioned 

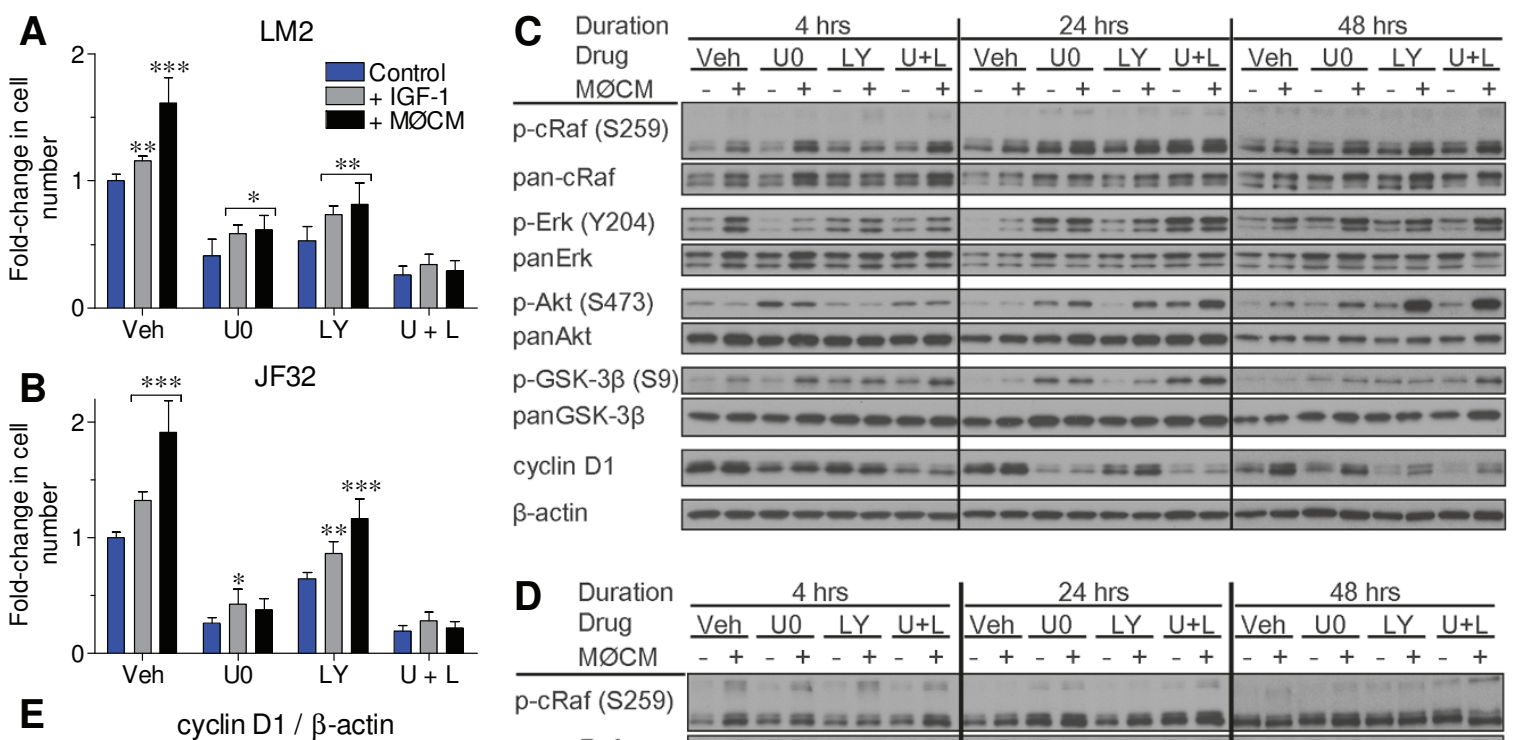

panAkt

p-GSK-3ß (S9)

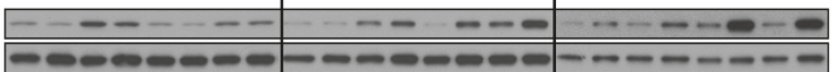

panGSK-3 3

cyclin D1

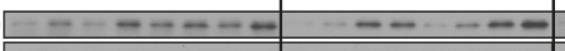

$\beta$-actin

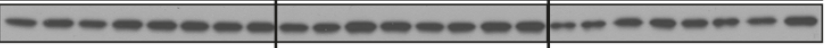

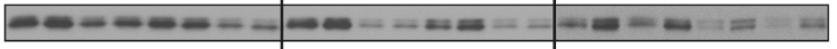

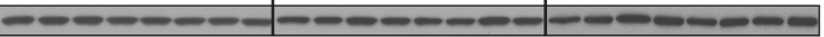

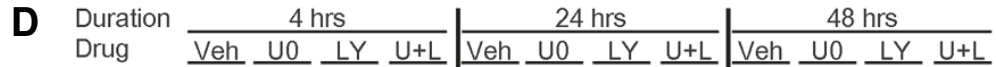
\begin{tabular}{c}
$\mathrm{M} \varnothing \mathrm{CM}$ \\
\hline -cRaf $(\mathrm{S} 259)$
\end{tabular}

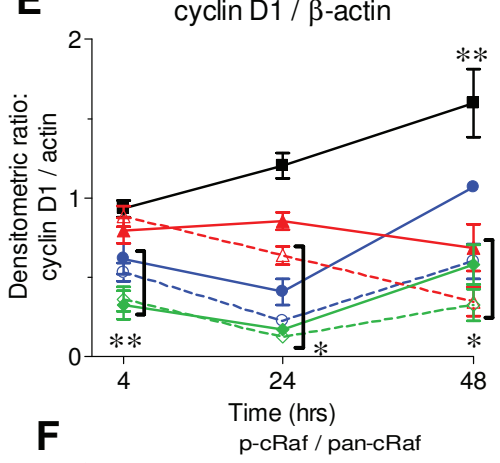

pan-cRaf

p-Erk (Y204)

panErk

p-Akt (S473)

panAkt

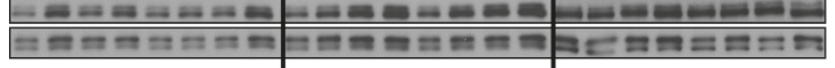

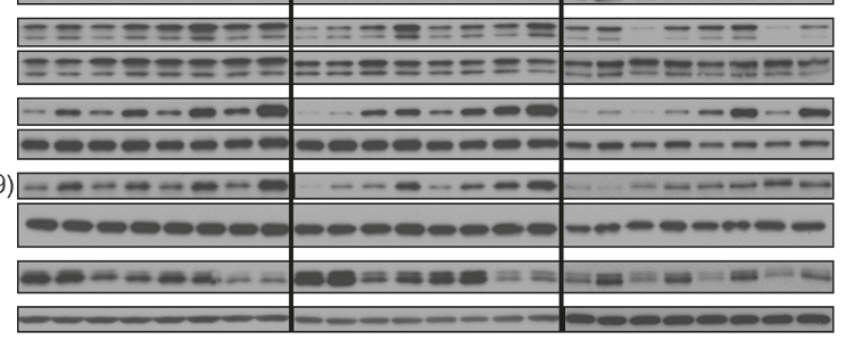

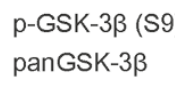

cyclin D1

$\beta$-actin
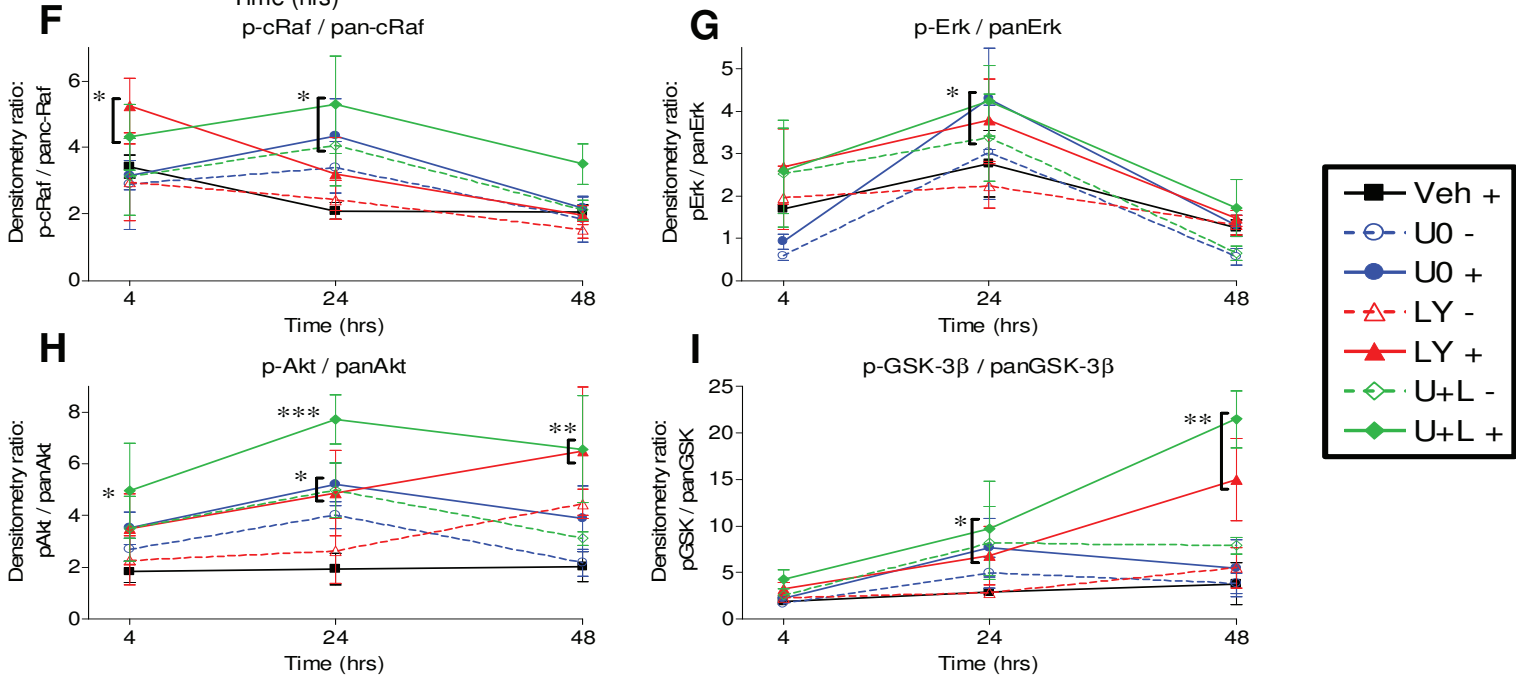

Figure 9 MEK and PI3K inhibition blocks MøCM induced growth, but dissociates kinase activity from cyclin D1 expression. A-B: (A) LM2 or (B) JF32 cells were cultured alone (Control), with $2 \mathrm{ng} / \mathrm{mL}$ mlGF-1 (+ IGF-1) or with media conditioned by MH-S macrophages (+ MØCM), and

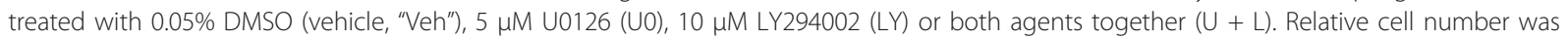
determined by MTS, and mean + SD plotted as fold-change from vehicle control, which was normalized to 1.0. Data was pooled from at least 3 independent experiments. * $P<0.05$, ** $P<0.01$ and ${ }^{* * *} P<0.001$ versus control for each treatment by 2-way ANOVA. C-D: LM2 (C) or JF32 (D) cells were cultured as described above, and cell homogenates probed for protein expression as described. Western blot images are representative of two independent experiments. E-I: densitometry data from all western blot replicates was collected from both LM2 and JF32 cell lines, combined, and presented as fold change (mean \pm SEM) from untreated vehicle control lanes at each time point ("Veh -" group normalized to 1, not shown). The legend colors indicate drug treatment groups, followed by a "- or + " to indicate the absence or presence of $\mathrm{M} \varnothing \mathrm{CM}$, as in $(A-B){ }^{*} P<0.05,{ }^{* *} P<0.01$ and ${ }^{* *} P<0.001$ versus control (Veh -) cells at each time point by 2-way ANOVA. 


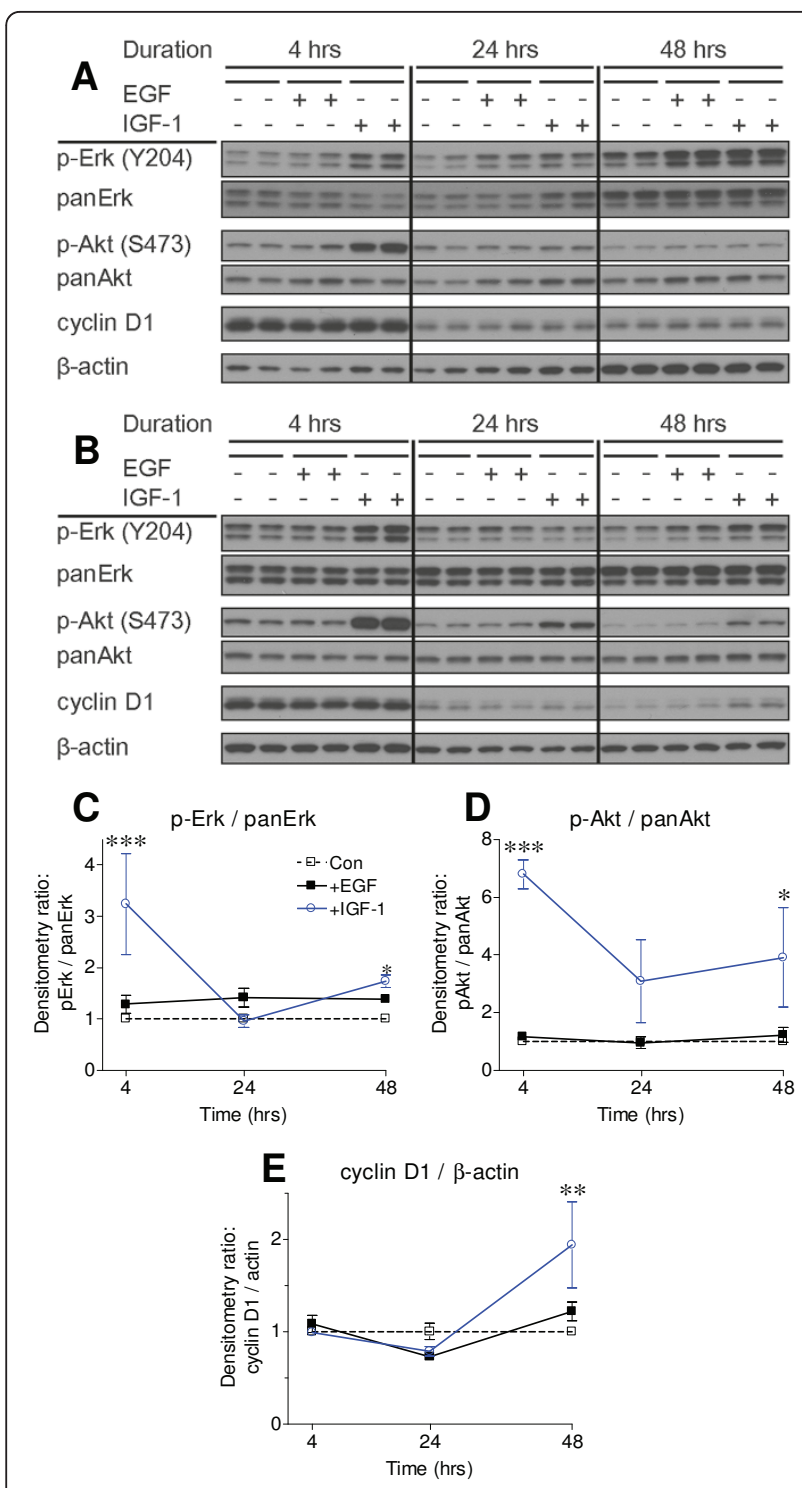

Figure 10 IGF-1 stimulates Erk and Akt activities and elevates cyclin D1 expression. A-B: (A) LM2 or (B) JF32 cells were cultured in serum-free media, with or without $2 \mathrm{ng} / \mathrm{mL} \mathrm{mlGF}-1$ or $\mathrm{mEGF}$, and cell homogenates were probed for protein expression. C-E: densitometry from western blot replicates from LM2 and JF32 cell lines was combined, and presented as fold change (mean \pm SEM) from untreated vehicle control lanes at each time point. ${ }^{*} P<0.05$, ${ }^{* *} P<0.01$ and ${ }^{* * *} P<0.001$ versus control (Veh - ) cells at each time point by 2-way ANOVA.

media and 40-times higher than what is detected in BAL fluid, Erk1/2 activity was not significantly elevated and Akt levels were unaffected (Figure 10C, D). EGF may partially stimulate Erk1/2 activity at supra-physiological levels, but this was not sufficient to stimulate cellular growth. When administered at cell-and tissue-relevant levels, IGF-1 stimulated both Erk1/2 and Akt activation, elevated cellular cyclin D1 content, and induced neoplastic proliferation.

\section{Discussion}

Our results suggest that inflammatory macrophages directly stimulate lung tumor growth through increased local production of IGF-1. We show that both naïve and tumor-educated primary lung macrophages stimulate the proliferation of lung epithelial cells in vitro; recombinant IGF-1 recapitulates this effect, and the degree of macrophage-induced growth stimulation correlates with media IGF-1 levels. IL-4 stimulates primary lung macrophages to produce significantly more IGF-1 in vitro. Tumor-educated macrophages produce more IGF-1 on a per-cell basis than naïve BAL macrophages, consistent with the elevated levels of $\mathrm{T}_{\mathrm{H}}$ 2-like cytokines reported in the lung tumor microenvironment. Secretory products of macrophages stimulate neoplastic Erk1/2 and Akt activity, increase cyclin D1 expression, and accelerate growth. Both macrophage conditioned media (MØCM) and recombinant IGF-1 stimulate neoplastic proliferation, which can be ablated by the combined inhibition of MEK and PI3K.

Sustained changes in macrophage phenotype exacerbate several lung diseases, and alternative macrophage activation is an early event in lung tumorigenesis $[6,42,43] . T_{H} 2$ cytokine levels rise in AC-bearing mice and human NSCLC patients, and alternative activation resulting from $\mathrm{T}_{\mathrm{H}}$ 2-like cytokines increases IGF-1 macrophage production $[11,38,39,44]$. Selectively removing alternatively-activated macrophages reduced lung tumor colonization in mice [45]. In agreement with these reports, we show that in vitro IL-4 stimulation enhanced IGF-1 production by primary BAL macrophages. Tumoreducated BAL macrophages produced significantly more IGF-1 than naïve macrophages, both basally and in response to IL-4 stimulation. We previously found that lung tumors recruit increasing numbers of macrophages to the alveolar space [6]. Therefore, the lung tumor environment contains not only more macrophages, but macrophages with heightened IGF-1 production. Consistent with this conclusion, BALF IGF-1 levels were $>3$ fold higher in lung tumor-bearing mice compared to naïve littermates (Figure 6A-B).

While the role of primary lung macrophages in mediating lung cancer proliferation has not been previously examined, the effects of co-cultured stromal cell types on a Kras mutant mouse lung AC cell line (LKR-13) was recently reported [18]. When cultured with media conditioned by $\mathrm{MH}-\mathrm{S}$ cells, proliferation of AC cells increased significantly, in agreement with our observations. This study focused on the migration resulting from the increased CXCL1 (KC) and IL-18 observed under co-culture conditions, and did not determine if exogenous KC or IL-18 stimulated neoplastic proliferation. They also found that MH-S conditioned media had no effect on neoplastic colony formation in soft agar, 
while we describe the potent stimulation of anchorageindependent growth of two Kras mutant lung tumorderived cell lines, using two independent assays (Figure 1). By fractionating MØCM, we demonstrate that the factors responsible for stimulating neoplastic proliferation are 7$11 \mathrm{kDa}$, making IL-18 (18 kDa) an unlikely candidate. KC, on the other hand, is a potent $8 \mathrm{kDa}$ chemokine. Based on molecular weight alone, we cannot rule out $\mathrm{KC}$ as contributing to the increased growth caused by MØCM; however, several lines of evidence make this unlikely. First, both $\mathrm{MH}-\mathrm{S}$ and primary naïve BAL macrophages stimulate neoplastic proliferation, but $\mathrm{KC}$ was undetectable in media conditioned by MH-S macrophages [18] or primary BAL macrophages isolated from naïve or lung-tumor bearing animals (data not shown). Second, unlike IGF-1, KC expression does not increase in alternatively activated macrophages [11]; alternative activation increases IGF-1 production, and this stimulates neoplastic proliferation. Lastly, although Zhong, et. al. examined an exhaustive array of cytokines, they did not measure IGF-1 [18]; thus, they did not evaluate the role of IGF-1 in mediating the effects observed in their co-culture model. Our observations of lung macrophages complement previous reports regarding stromal cell stimulation of neoplastic growth and invasion, and expand upon them to demonstrate that macrophage-derived IGF-1 accelerates neoplastic lung cell growth in vitro. Macrophage IGF-1 may thus have a pathological role in lung cancer.

Direct connections between lung macrophages and AC progression in vivo are less clear than the welldescribed interactions between macrophages and breast cancer cells $[14,16]$, or osteoclasts and oncolytic breast cancer metastases [46]. Lung tumor cells over-expressing IL- $1 \beta$ enhanced macrophage recruitment and tumor angiogenesis when implanted into syngeneic mice [19]. In our studies, BALF CSF-1 levels were nearly undetectable while IL-1 $\beta$ levels were significantly higher in tumor-bearing lungs vs. naïve (data not shown). However, recombinant IL-1 $\beta$ did not affect the proliferation of neoplastic lung epithelial cells in vitro, either alone or in combination with IGF-1. IL-1 $\beta$ also did not significantly affect IGF-1 production by MH-S macrophages (data not shown). Although not responsible for the macrophage-induced neoplastic proliferation observed in our studies, IL-1 $\beta$ stimulated macrophages produce more pro-angiogenic factors, and this interleukin may contribute to the increased numbers of macrophages in tumor-bearing lungs $[6,10,19]$.

In lung cancer therapy, anti-angiogenic or anti-inflammatory agents show widespread efficacy across many cancer types, while inhibition of the EGF receptor (EGFR) is mainly effective in the NSCLC sub-population containing activating EGFR mutations [40,47]. EGFRmutant lung cancers eventually become resistant to
anti-EGFR therapies, and then progress rapidly $[12,40]$. One proposed mechanism for lung cancer resistance to anti-EGFR therapy is the increased expression of other EGFR family receptors and/or the IGF-1 receptor [48]. Similar to the well-described hetero-dimerization among the EGF receptor family, IGF-1R can form functional complexes with EGFR [12,48]. Unlike IGF-1R, EGFR can be stimulated by numerous EGF-like factors, which macrophages produce in a tissue and disease-specific manner $[10,14,49]$. However, we show that: 1) BALF EGF levels are very low and do not differ between naïve and tumor-bearing lungs; 2) macrophages produce trace amounts of EGF in vitro; and 3) EGF does not stimulate neoplastic lung proliferation either alone or in combination with IGF-1 or MØCM (Figures 6, 7 and data not shown). Combined, these observations indicate that EGF is not involved in the macrophage-stimulation of pulmonary epithelial growth in vitro, and argue against significant lung macrophage EGF production in vivo. The increased EGFR phosphorylation in primary mouse lung tumors bearing Kras mutations that we previously reported could result from IGF-1R/EGFR coupling and trans-activation after IGF-1 stimulation $[48,50]$. Mutations in EGFR and KRAS are mutually exclusive in both human and murine NSCLC, and EGF stimulation would not be expected drive Kras mutant models of lung cancer $[23,40,50]$. A requirement for the IGF-1 receptor in mediating lung cancer growth is consistent with other reports that IGF-1 stimulates rapid anchorage-independent growth in vitro, while IGF-1R inhibition slows tumor growth in both animal xenograft studies [27] and human clinical trials [12].

IGF-1R signals through numerous downstream pathways in which the intracellular kinases Erk1/2 and Akt are frequently activated $[12,48]$. We have previously determined that MEK inhibition induces a potent G1 phase arrest in neoplastic lung cell cycle progression in vitro [51], and others have determined that blocking both MEK and PI3K slows lung tumor growth in vivo [25]. We show herein that MØCM-stimulated neoplastic proliferation significantly increases cyclin D1 expression, which is abrogated by the combined inhibition of both MEK and PI3K. Sole inhibition of either MEK or PI3K partially limits macrophage stimulation of LM2 and JF32 growth to slightly different extents. While MØCM modestly increases Erk1/2 and Akt activity, long-term MEK and PI3K inhibition strikingly stimulates both kinases in an additive manner with conditioned media treatment. This increased kinase activity resulting from MEK and PI3K inhibition, however, is no longer associated with changes in cyclin D1, as combined inhibition resulted in the highest levels of Akt activity, but lowest levels of cyclin D1 expression ("U + L"; Figure 9E and 9H). Compensatory Akt or Erk activation in response to 
upstream kinase inhibition is consistent with the extensive cross-talk that exists among MAPK pathways, where inhibition of any single mediator results in exaggerated and/or sustained signaling through an alternate pathway $[32,34,52,53]$. Indeed, when the MEK pathway was inhibited in LM2 cells, early p-Akt activity increased, while PI3K inhibition increased p-Erk1/2 (4 hrs: Figure 9C). Akt is hyper-phosphorylated with $24 \mathrm{hrs}$ of treatment with either MEK or PI3K inhibitor, and this hyper-activated Akt sustains 5-10 higher levels of pGSK-3 $\beta$ and p-cRaf for at least 48 hrs. Erk1/2 phosphorylation is also stimulated by drug treatment, which peaks at $24 \mathrm{hrs}$ and rapidly declines by $48 \mathrm{hrs}$. Consistent with our observations, continuous hyper-activation of Akt or Erk1/2 induces cytostasis or even apoptosis in some tissues, while more modest Erk1/2 activation drives Kras mutant tumor cell proliferation [34,40,51]. While our studies demonstrate that MØCM and IGF-1 stimulated neoplastic growth is affected similarly by MEK and PI3K inhibition, further studies in geneticallysilenced or kinase-mutant cell lines are required to determine the discrete cellular mechanisms necessary for growth factor-stimulated neoplastic proliferation.

Kras mutant lung tumors may rely on growth factor stimulation in vivo to regulate binding partner localization and activation. Kras can only efficiently trigger proliferation by recruiting partner kinases like cytosolic Raf (cRaf/Raf-1) to the plasma membrane, where cRaf is phosphorylated and activated by ligand-bound growth factor receptors [33,54]. By phosphorylating mutant Kras-bound cRaf, growth factors can potently engage the ras-Raf signaling cascade, which deactivates slowly due to decreased GTPase activity of mutant Kras $[24,54]$. Akt phosphorylates cRaf at S259, which creates a binding domain for 14-3-3 protein family members [32,33]. 14-3-3 binding is required to inactivate cRaf, as p-S259 alone does not affect cRaf activity. However, mutant Kras can displace 14-3-3 from the p-S259 region of cRaf [33]. Thus, active Akt could phosphorylate and inactivate cRaf, leading to decreased Erk1/2 signaling, but cells with mutant Kras can bypass this regulatory mechanism and maintain high cRaf activity [33,54]. Consistent with these reports, we observe significant increases in neoplastic Akt, cRaf and Erk1/2 phosphorylation, suggesting that these Kras mutant cells bypass Akt-mediated MEK pathway inactivation (Figures 3 and 9). Due to the complex interactions between Erk and Akt, IGF-1 stimulated growth regulation in Kras-mutant NSCLC cells should be the subject of future investigation.

\section{Conclusions}

In summary, we have identified IGF-1 as one factor produced by alveolar macrophages that directly stimulates neoplastic lung proliferation in vitro. These findings, in combination with correlations between macrophage numbers, activation state and IGF-1 levels in vivo, imply that IGF-1 mediates macrophage stimulation of NSCLC growth. This additional evidence links previous observations of macrophage depletion to tumor growth suppression. Macrophages are crucial for the progression of numerous cancers, including lung cancer, and IGF-1 has long been associated with resistance to chemotherapy and increased neoplastic proliferation.

Our results suggest that current anti-growth factor therapy could be augmented by removing the stromal source of neoplastic growth stimulation, in addition to blocking discrete elements of downstream signal transduction. This may be an effective strategy for the treatment of lung cancer and other diseases in which macrophage recruitment is associated with aberrant tissue proliferation.

\section{Methods}

Mice

Male A/J mice (4-6 wks old) were purchased from the Jackson Laboratory (Bar Harbor, ME), housed on hardwood bedding with $12 \mathrm{hr}$ light/dark cycles, and fed Harlan Teklad 22/5 rodent chow ad libitum (Harlan, Madison, WI) at the Center for Comparative Medicine in the University of Colorado, Anschutz Medical Campus. Procedures were approved by the Institutional Animal Care and Use Committee of the University of Colorado.

\section{Isolation of lung protein exudates and alveolar macrophages}

Primary alveolar macrophages and lung protein exudates were isolated by bronchoalveolar lavage (BAL) from male A/J mice 24-32 wks after a single i.p. injection of $10 \mathrm{mg} / \mathrm{g}$ ethyl carbamate (urethane; Alfa Aesar; Heysham, Lancashire. U.K.) or $0.9 \% \mathrm{NaCl}$ vehicle control, as previously described $[6,55]$. This dose of urethane induces multiple lung tumors in $\mathrm{A} / \mathrm{J}$ mice, which are mainly adenomas at $24 \mathrm{wks}$ and progress to AC from 24-42 wks. BAL macrophages from control animals are considered "naïve", while macrophages isolated from lung tumor-bearing mice are "tumor-educated" [14].

\section{Generation of JF32 cells from primary lung tumor isolates} Thirty-two wks after urethane injection, male A/J lung tumors were resected from the lung under a dissecting microscope. Fifty mg of tumor tissue was placed onto a sterile Pyrex petri dish, finely chopped in $0.2 \mathrm{~mL}$ PBS with a sterile razor, and the resulting suspension added to a Krebs-Ringer buffered solution containing $10 \mathrm{U} / \mathrm{mL}$ Dispase $10 \mathrm{U} / \mathrm{mL}$ collagenase I (Worthington, Lakewood, NJ.). The tumor suspension was digested with 
agitation for $60 \mathrm{~min}$. at $37^{\circ} \mathrm{C}$, after which digestion was terminated by adding an equal volume of $20 \mathrm{mM}$ EDTA. The tumor suspension was then passed twice through a 20 ga syringe needle, and filtered to create a single cell suspension of tumor cells, as described for the isolation of primary Clara cells [56,57]. These tumor cells were washed 3-times in 10\% FBS (Hyclone; Logan, UT) MEM- $\alpha$ (Invitrogen; Carlsbad, CA), collected by centrifugation, and their viability determined by trypanblue (Sigma-Aldrich; St. Louis, MO) exclusion using a hemocytometer. The primary tumor isolates were $>90 \%$ viable by this method. Twenty thousand cells per well were plated in 1\% FBS MEM- $\alpha$ on Matrigel-coated 6well plates (Fisher; Waltham, MA). The primary tumor cell cultures were maintained for 4 weeks, and MEM- $\alpha$ media containing 1\% FBS changed once weekly. For three weeks, there was little morphological change in colony size or number, and then actively proliferating colonies were observed. Two adherent colonies were removed (using a trimmed pipette tip), designated "JF32a" and "JF32b", plated onto standard $100 \mathrm{~mm}$ tissue culture-treated plates, and cultured as described below. Exon 2 of the Kras gene was sequenced as previously described [50], and Q61R Kras mutations detected in both JF32a and b, consistent with our previously published report of Kras mutation incidence in urethane-induced mouse lung tumors [50].

\section{Cell culture}

The non-tumorigenic, mouse type II pneumocytederived epithelial cell line (E10) was used to represent non-transformed lung epithelium in vitro. To study the interactions of tumor cells with macrophages, three neoplastic mouse lung cell lines were used: the newly generated JF32a cells (hereafter "JF32"); LM2, previously derived from a urethane induced lung tumor in $\mathrm{A} / \mathrm{J}$ mice; and $\mathrm{E} 9$, a spontaneous transformant of E10 cells [57]. Culture of all cell lines was previously described; JF32 cells were maintained like the LM2 cell line $[21,57]$. To study the in vitro effects of immune mediators on epithelial cells, $\mathrm{MH}-\mathrm{S}$ macrophages (American Type Culture Collection; Manassas, VA), an alveolar macrophage cell line isolated from a $\mathrm{BALB} / \mathrm{c}$ mouse [58], or primary BAL macrophages were used. All macrophages were maintained in RPMI 1640 (Invitrogen) according to ATCC guidelines for the MH-S cell line. All cells were cultured in a humidified atmosphere of $5 \% \mathrm{CO}_{2}$ in ambient air at $37^{\circ} \mathrm{C}$, and routinely screened for $\mathrm{Myco-}$ plasma contamination (MD Biosciences Inc; St. Paul, $\mathrm{MN})$. Where indicated, $2-50 \mathrm{ng} / \mathrm{mL}$ recombinant mouse IGF-1 (R\&D Systems, Inc.; Minneapolis, MN.) and/or EGF (eBioscience, Inc.; San Diego, CA) were added to epithelial cultures.

\section{Anchorage-independent culture}

LM2 and JF32 cells were suspended in 0.5\% low-melting point agarose (Ultra-pure LMP agarose, Invitrogen) in MEM- $\alpha$ media containing $0.5 \%$ BSA (Sigma), and plated at 1,000 cells/well into 12 well plates with a pre-coated base layer of $1 \%$ agar (Sigma), and a top layer of $0.75 \%$ LMP agarose. Once weekly, cells were fed with $0.5 \mathrm{~mL}$ MEM- $\alpha+0.5 \%$ BSA or macrophage-conditioned media (with $0.5 \%$ BSA, described below). After 5-6 wks of growth, colony number (clumps of $\geq 10$ cells) was determined under $20 \times$ magnification with a bright-field inverted microscope (Nikon Instruments Inc, Melville, NY). Alternatively, neoplastic cells were suspended in MEM- $\alpha$ media containing $0.5 \%$ BSA, and plated at 3,000 cells/well onto ultra-low attachment 6 -well culture plates (Costar, Corning, NY). Cells were fed once weekly with 1 mL MEM- $\alpha+0.5 \%$ BSA or macrophage-conditioned media. After 3 wks, the contents of each well were removed with a pipette, and cells pelleted by $5 \mathrm{~min}$. centrifugation at $600 \times \mathrm{g}$. Cells were resuspended in $1.5 \mathrm{~mL}$ Accutase (Sigma), and incubated for $20 \mathrm{~min}$. at $37^{\circ} \mathrm{C}$ to create a single-cell suspension. Equal volumes of cell suspension were added to $0.4 \%$ Trypan-blue solution (Sigma), and live vs. dead cells ascertained using a hemocytometer.

\section{Macrophage co-culture and conditioned media}

Epithelial cell lines were plated onto tissue culture-treated plates (Costar). Macrophages were plated onto 0.4 $\mu \mathrm{m}$ pore Transwell inserts (Becton Dickinson, Franklin Lakes, NJ) to allow diffusible signals to exchange during co-culture while preventing physical contact. Epithelial cells and macrophages were plated separately in media containing $10 \%$ FBS and allowed to equilibrate overnight. All co-culture systems consisted of macrophages co-incubated with epithelial cells at a 1:5, macrophage to epithelial cell ratio (2-4 wells/condition). Co-culture was initiated by replacing the original media with fresh serum-free MEM- $\alpha+1 \%$ BSA media (SF MEM- $\alpha$ ), and inserting the macrophage-containing Transwells into wells containing epithelial cells. To study the direct effects of macrophage-derived molecules on epithelial cells, media conditioned by primary BAL macrophages was generated by culturing 100,000 macrophages in 24well plates in $1 \mathrm{~mL}$ media for $24 \mathrm{hrs}$. This macrophageconditioned media (MØCM) was then added to epithelial cell-containing wells at a 1:1 ratio with fresh media. For additional experimental analysis, SF MEM- $\alpha$ media was conditioned by $\mathrm{MH}-\mathrm{S}$ macrophages at 1 million macrophages $/ \mathrm{mL}$ for $24 \mathrm{hrs}$, and added to cells as above.

\section{Conditioned media fractionation and IGF-1 immuno- depletion}

MØCM from MH-S macrophages was collected and filtered through Microcon $0.5 \mathrm{~mL}$ volume spin filters 
(Millipore, Bellerica, MA), with molecular-weight cutoffs (m.w.c.o.) of 3, 10 and $30 \mathrm{kDa}$, as indicated. Each column was rinsed $2 \times$ with PBS, and then $500 \mu \mathrm{L}$ of MØCM or control SF MEM- $\alpha$ media applied and columns centrifuged at $11,000 \times \mathrm{g} @ 10^{\circ} \mathrm{C}$ until only $~ 50$ $\mu \mathrm{L}$ remained. The concentrated media was removed and added to LM2 containing wells in $500 \mu \mathrm{L}$ of fresh SF MEM- $\alpha$. IGF-1 was depleted from MØCM following the method described by Wynes, et. al., with several modifications [39]. Conditioned media was first concentrated 4-times against a 3,000 kDa m.w.c.o. Amicon filter using a nitrogen pressure filtration chamber (Millipore) to yield a final IGF-1 concentration of 3-4 $\mathrm{ng} / \mathrm{mL}$. This MØCM concentrate was rotated for $2 \mathrm{hrs}$ with $6 \mu \mathrm{g}$ of $\alpha$-mIGF-1 IgG antibodies, consisting of a 1:1:1 w/w ratio of: MAB791, AF791 (R\&D systems, Inc) and sc-1422 (Santa Cruz Biotechnology, Inc, Santa Cruz, CA). As an IgG control, $6 \mu \mathrm{g}$ of goat IgG $\alpha-\mathrm{COX}-1$ antibody (sc-1754, Santa Cruz) was used. Fifty $\mu \mathrm{L}$ of protein G-coated magnetic resin, prepared and washed as directed (DynaMax; Invitrogen), was added to the media + antibody solution, and rotated for $1 \mathrm{hr}$. The resin was separated from the solution with a Dynal bench-top magnet (Invitrogen) and discarded, while the MØCM was transferred to a sterile eppendorf tube. This process was repeated with fresh antibody prior to cell treatment.

\section{MH-S siRNA transfection}

$\mathrm{MH}-\mathrm{S}$ macrophages were transfected with siRNA targeted against murine IGF-1 according to manufacturer instructions for murine J774.1 macrophage transfection (Qiagen Inc, Valencia, CA), and then optimized for MH-S transfection as described below. Three $\alpha$-IGF-1 siRNA constructs, SI01073996, SI01073982 and SI01073989 (Qiagen; http://www.qiagen.com/geneglobe), were evaluated for IGF-1 knockdown, as determined by IGF-1 levels in conditioned media. Knockdown efficiency was compared against naïve (untransfected) and AllStars negative control (scrambled siRNA) transfected cells; the AllStars negative control has no known homology to any mammalian gene (Qiagen). Constructs “...96" and "...82" were no more effective than the negative control, while "...89" (hereafter referred to as " $\alpha$-IGF-1 siRNA") effectively knocked down IGF-1 release into culture media. The transfection reagent HiPerFect (Qiagen) exhibited low toxicity and was used to establish transfection conditions that maintained $\geq 80 \%$ viability in transfected cells vs. naïve. In brief, 150,000 MH-S macrophages/well were suspended in $200 \mu \mathrm{L}$ of $10 \%$ FCS supplemented RPMI in 24-well plates and allowed to incubate as described above for 1-2 hrs. For each well, siRNA $(1.5 \mu \mathrm{L}$ of a $20 \mu \mathrm{M}$ stock solution) was added to $100 \mu \mathrm{L}$ of serum-free RPMI and vortexed prior to addition of $4.5 \mu \mathrm{L}$ HiPerFect transfection reagent.
After 4 hrs, $150 \mu \mathrm{L}$ of $10 \%$ FCS RPMI was added; 12 hrs later another $150 \mu \mathrm{L}$ of $10 \%$ FCS RPMI was added. After $48 \mathrm{hrs}$, the transfection media was removed and replaced with SF MEM- $\alpha+0.5 \%$ BSA, which $\mathrm{MH}-\mathrm{S}$ macrophages conditioned for 24 hrs. Successful IGF-1 depletion was monitored by ELISA, as described.

\section{Cell proliferation and viability}

Relative cell number was determined by 3-(4,5dimethylthiazol-2-yl)-5-(3-carboxymethoxyphenyl)-2-(4sulfophenyl)-2H-tetrazolium assay (MTS;CellTiter $96^{\circledR}$ One AQueous, Promega; Madison, WI) according to manufacturer's instructions, and measured spectrophotometrically at $\mathrm{Abs}_{490 \mathrm{~nm}}$ (Vmax, Molecular Devices; Sunnyvale, CA). Additionally, cells were trypsinized, collected and counted with a hemocytometer after trypanblue staining. All cell counts were normalized to control values for each cell line or treatment group, unless otherwise indicated.

\section{Determination of IGF-1 and EGF levels}

IGF-1 and EGF were separately measured in biological samples by enzyme-linked immunosorbant assay (ELISA) in a 96-well format, according to the manufacturer's directions (R\&D Systems, Inc.), and measured spectrophotometrically at $\mathrm{Abs}_{450 \mathrm{~nm}}$ with wavelength correction set to $\mathrm{Abs}_{550 \mathrm{~nm}}$. All samples were diluted to be within the middle $60 \%$ of the 8 -point standard curve, and concentrations calculated from log-transformed absorbance values, as recommended. In addition to standard curves, every plate contained an independent calibrator sample that tested within the range provided.

\section{Immunoblotting}

Epithelial cell protein lysates were harvested after $48 \mathrm{hrs}$ co-culture with $\mathrm{MH}-\mathrm{S}$ macrophages (+), empty inserts (-, controls) or at the indicated time after conditioned media or growth factor addition (+), and compared to control wells without MØCM (-) as described [21,50], with the following modifications. Protein (5-10 ug/lane) was applied to 4-20\% Tris-SDS Criterion gels (Bio-Rad, Hercules, CA), and separated proteins electrotransferred onto Immobilon-P PVDF membranes (Millipore). The membranes were blocked for $30 \mathrm{~min}$. at room temperature in $100 \mathrm{mM}$ Tris-buffered saline $\mathrm{pH}$ 7.4 with $0.1 \%$ Tween-20 (TBST) supplemented with the indicated concentration of non-fat dry milk, and incubated overnight at $4^{\circ} \mathrm{C}$ with primary antibodies diluted in blocking buffer with milk or bovine serum albumin (BSA; Sigma), as described in Table 1 [51]. After washing, blots were incubated with horseradish-peroxidase conjugated secondary antibodies at the indicated dilution for $1 \mathrm{hr}$ at room temperature (Table 1), and protein bands were visualized by chemiluminescence on X-ray 
Table 1 Western blot antibody dilution

\begin{tabular}{|c|c|c|c|c|}
\hline $\begin{array}{l}\text { Antibody } \\
\text { Target }\end{array}$ & $\begin{array}{c}\text { Blocking/Antibody Dilution } \\
\text { Buffer* }\end{array}$ & $\begin{array}{c}\text { Primary Antibody } \\
\text { Dilutiont }\end{array}$ & $\begin{array}{l}\text { Secondary Antibody } \\
\text { Dilution }\end{array}$ & $\begin{array}{l}\text { Antibody Source }\left(1^{\circ}\right) \\
\left.2^{\circ}\right) \neq\end{array}$ \\
\hline p-cRaf (S259) & TBST $+5 \%$ milk & $1: 2,000(5 \%$ BSA) & 1:10,000 goat anti-rabbit & CST/CST \\
\hline c-Raf & TBST $+5 \%$ milk & $1: 1,000(5 \%$ BSA) & $1: 10,000$ goat anti-rabbit & CST/CST \\
\hline pErk1/2 (Y204) & TBST $+2 \%$ milk & $1: 1,000$ & 1:20,000 goat anti-mouse & S.C./S.C. \\
\hline Erk1/2 & TBST $+2 \%$ milk & $1: 50,000$ & 1:40,000 goat anti-rabbit & S.C./S.C. \\
\hline pAkt (\$473) & TBST $+5 \%$ milk & $1: 4,000(5 \%$ BSA) & 1:10,000 goat anti-rabbit & CST/CST \\
\hline Akt & TBST $+5 \%$ milk & $1: 10,000$ (5\% BSA) & $1: 20,000$ goat anti-rabbit & CST/CST \\
\hline pGSK-3ß (S9) & TBST $+5 \%$ milk & $1: 1,000(5 \%$ BSA) & 1:10,000 goat anti-rabbit & CST/CST \\
\hline panGSK-3 $\beta$ & $\mathrm{TBST}+5 \%$ milk & $1: 2,000(5 \%$ BSA) & 1:10,000 goat anti-rabbit & CST/CST \\
\hline Cyclin D1 & TBST $+5 \%$ milk & $1: 2,000(5 \%$ BSA) & 1:10,000 goat anti-rabbit & CST/CST \\
\hline$\beta$-actin & TBST $+2 \%$ milk & $1: 100,000$ & 1:100,000 goat anti-mouse & Sigma/S.C. \\
\hline
\end{tabular}

*TBST, $100 \mathrm{mM}$ Tris-buffered saline $\mathrm{pH} 7.4$ with $0.1 \%$ Tween-20. $\dagger$ BSA, bovine serum albumin. $\neq$ Primary $\left(1^{\circ}\right)$ and secondary $\left(2^{\circ}\right)$ antibodies were obtained from Sigma, Santa Cruz Biotechnology, Inc. (S.C.; Santa Cruz, CA) and Cell Signaling Technology (CST).

film as previously described [50]. Antibodies against phospho-specific proteins were applied to freshly transferred membranes. After detection, membranes were stripped with $1 \mathrm{M}$ Tris- $\mathrm{HCl}$ ( $\mathrm{pH}$ 6.7) buffer containing $2 \%$ SDS and $0.86 \%$ 2-mercaptoethanol (Fisher) in a $50^{\circ} \mathrm{C}$ hybridization oven for $60 \mathrm{~min}$., and probed with antibodies against total protein levels as indicated. Equal protein loading was confirmed by $\beta$-actin levels and Coomassie gel staining (Fisher). Band density was quantified by Un-Scan-It software (Silk Scientific, Orem, $\mathrm{UT}$ ), and values normalized either to $\beta$-actin or relevant total protein bands on each PVDF membrane.

\section{Drug treatment of cells}

To selectively block activation of the Erk and Akt signaling pathways, selective inhibitors of MEK (U0126; Promega) and PI3K (LY294002; Cell Signaling Technology, Beverly, MA) were used at $5 \mu \mathrm{M}$ and $10 \mu \mathrm{M}$, respectively [37]. Drugs were dissolved in DMSO in amber tubes immediately prior to use, and added in SF MEM$\alpha$ to cells cultured alone, with MH-S macrophages, with МØCM, or with recombinant growth factors for $72 \mathrm{hrs}$. The concentration of DMSO in all experiments never exceeded the vehicle control of $0.05 \%$. To selectively block IGF-1R signaling, NVP-AEW541 (Cayman Chemical Company; Ann Arbor, MI) was directly dissolved in to $0.5 \%$ BSA-supplemented MEM- $\alpha$ media, and added to cell-containing wells at a final concentration of $5 \mu \mathrm{M}$.

\section{Statistical analysis and estimation}

To estimate the size of the MØCM factor responsible for stimulating neoplastic proliferation, we derived a function describing the extent of tumor cell growth (y) in terms of the size of molecules predicted to be contained in isolated fractions of conditioned media (x). The percent retention on size-exclusion columns (as fractions of the amounts loaded) vs. protein size $(\mathrm{kDa})$ on each size m.w.c.o. column was provided by the manufacturer (Millpore) for six recombinant proteins of varying size. The resulting data set was plotted as percent retained vs. protein size, and the least complex "best-fit" equation was obtained using non-linear regression with SigmaPlot 2001 ver 7.101 (SysStat Software Inc., San Jose, CA). The extent that total, unfractionated MØCM stimulated LM2 proliferation was normalized to $100 \%$. The extent that each retentate fraction stimulated LM2 growth was similarly calculated to determine the remaining percent of "growth stimulating ability" after filtration, as compared to unfractionated MØCM. The percent of growth stimulus remaining was equated to the percentage of protein standard retained, and the resulting protein size estimate calculated from the bestfit equation.

Densitometry measurements are presented as means \pm SEM, and all other measurements as means \pm SD [59]. Differences between conditions at specific time points were examined using Student's unpaired t-test when comparing only two groups, with Welch's correction for unequal variance when appropriate. For multiple comparisons, one-way and two-way ANOVA were used to compare interactions between co-culture conditions and proliferation rates as recommended $[60,61]$. The Bonferroni correction was used for multiple comparisons during ANOVA analysis. Correlation was performed using the Pearson method, and the corresponding linear regression plotted. All statistical tests for significance and correlation were performed using GraphPad Prism version 4.02 (GraphPad Software; San Diego, CA.); differences were considered statistically significant when $P<0.05$.

\section{List of abbreviations}

Akt: protein kinase B; AC: adenocarcinoma; BAL(F) bronhoalveolar lavage (fluid); CRaf: cytosolic Ras-1 (MAP3K); CSF-1: colony-stimulating factor 1; EGF: epidermal growth factor; ELISA: enzyme-linked immunosorbant assay; Erk1/2: extracellular-regulated kinase 1/2; GM-CSF: granulocyte-monocyte colony stimulating factor; GSK-3 $\beta$ : glycogen synthase kinase $3 \beta$; IGF-1: insulin-like factor 1 ; IL-1 $\beta$ : interleukin-1 $\beta$; KC: keratinocyte-derived chemokine; MEK: 
mitogen-activated: extracellular regulated kinase (MAP2K); MØCM: macrophage-conditioned media; pan-: total levels; NSCLC: non-small cell lung cancer; PI3K: phosphoinositide 3-kinase.

\section{Acknowledgements}

JF is an American Foundation for Pharmaceutical Education Fellow. We thank Mr. Brad S. Barrett, Dr. Elizabeth F. Redente and Dr. Pamela L. Rice for their technical expertise and helpful discussions, and Dr. Rajesh Agarwal for helpful discussions and expert guidance. This work was supported by $\mathrm{NCl}$ grants CA33497 and CA132552.

\section{Authors' contributions}

JF participated in the study conception and design, performed the experimental work, analyzed and interpreted the data, and wrote the manuscript. LN participated in the design of the study, experimental work and data interpretation. AM participated in the study conception, and contributed to data interpretation. All authors read, revised and approved the final manuscript.

\section{Competing interests}

The authors declare that they have no competing interests.

\section{Received: 30 November 2010 Accepted: 24 June 2011}

Published: 24 June 2011

\section{References}

1. Jemal A, Siegel R, Xu J, Ward E: Cancer statistics, 2010. CA Cancer J Clin 2010, 60:277-300.

2. Schottenfeld D: Epidemiology of Lung Cancer. In Lung Cancer: Principles and Practice. Edited by: Pass HI, Mitchell JB, Johnson DH, Turrisi AT. Philadelphia: Lippincott-Raven Publishers; 1996:305-321.

3. Alberg AJ, Samet JM: In Biology of Lung Cancer. Edited by: Kane MA, Bunn PA. New York: Marcel Dekker, Inc.; 1998:11-52.

4. Lee JM, Yanagawa J, Peebles KA, Sharma S, Mao JT, Dubinett SM: Inflammation in lung carcinogenesis: new targets for lung cancer chemoprevention and treatment. Crit Rev Oncol Hematol 2008, 66:208-217.

5. Peebles KA, Lee JM, Mao JT, Hazra S, Reckamp KL, Krysan K, Dohadwala M, Heinrich EL, Walser TC, Cui X, Baratelli FE, Garon E, Sharma S, Dubinett SM: Inflammation and lung carcinogenesis: applying findings in prevention and treatment. Expert Rev Anticancer Ther 2007, 7:1405-1421.

6. Redente EF, Orlicky DJ, Bouchard RJ, Malkinson AM: Tumor signaling to the bone marrow changes the phenotype of monocytes and pulmonary macrophages during urethane-induced primary lung tumorigenesis in A/J mice. Am J Pathol 2007, 170:693-708.

7. Arenberg DA, Keane MP, DiGiovine B, Kunkel SL, Strom SR, Burdick MD, lannettoni MD, Strieter RM: Macrophage infiltration in human non-smallcell lung cancer: the role of CC chemokines. Cancer Immunol Immunother 2000, 49:63-70.

8. Ballaz S, Mulshine JL: The potential contributions of chronic inflammation to lung carcinogenesis. Clin Lung Cancer 2003, 5:46-62.

9. Johnson SK, Kerr KM, Chapman AD, Kennedy MM, King G, Cockburn JS, Jeffrey RR: Immune cell infiltrates and prognosis in primary carcinoma of the lung. Lung Cancer 2000, 27:27-35.

10. Coussens LM, Werb Z: Inflammation and cancer. Nature 2002, 420:860-867.

11. Martinez FO, Gordon S, Locati M, Mantovani A: Transcriptional profiling of the human monocyte-to-macrophage differentiation and polarization: new molecules and patterns of gene expression. J Immunol 2006 177:7303-7311.

12. Bauer AK, Dwyer-Nield LD, Keil K, Koski K, Malkinson AM: Butylated hydroxytoluene (BHT) induction of pulmonary inflammation: a role in tumor promotion. Exp Lung Res 2001, 27:197-216.

13. Condeelis J, Pollard JW: Macrophages: obligate partners for tumor cell migration, invasion, and metastasis. Cell 2006, 124:263-266.

14. Hagemann T, Wilson J, Kulbe H, Li NF, Leinster DA, Charles K, Klemm F, Pukrop T, Binder C, Balkwill FR: Macrophages induce invasiveness of epithelial cancer cells via NF-kappa B and JNK. J Immunol 2005, 175:1197-1205.

15. Wyckoff JB, Wang Y, Lin EY, Li JF, Goswami S, Stanley ER, Segall JE, Pollard JW, Condeelis J: Direct visualization of macrophage-assisted tumor cell intravasation in mammary tumors. Cancer Res 2007, 67:2649-2656.
16. Guth AM, Janssen WJ, Bosio CM, Crouch EC, Henson PM, Dow SW: Lung environment determines unique phenotype of alveolar macrophages. Am J Physiol Lung Cell Mol Physiol 2009, 296:L936-L946.

17. Zhong L, Roybal J, Chaerkady R, Zhang W, Choi K, Alvarez CA, Tran H, Creighton CJ, Yan S, Strieter RM, Pandey A, Kurie JM: Identification of secreted proteins that mediate cell-cell interactions in an in vitro model of the lung cancer microenvironment. Cancer Res 2008, 68:7237-7245.

18. Kimura YN, Watari K, Fotovati A, Hosoi F, Yasumoto K, Izumi H, Kohno K, Umezawa K, Iguchi H, Shirouzu K, Takamori S, Kuwano M, Ono M: Inflammatory stimuli from macrophages and cancer cells synergistically promote tumor growth and angiogenesis. Cancer Sci 2007, 98:2009-2018.

19. Pratilas CA, Hanrahan AJ, Halilovic E, Persaud Y, Soh J, Chitale D, Shigematsu H, Yamamoto H, Sawai A, Janakiraman M, Taylor BS, Pao W, Toyooka S, Ladanyi M, Gazdar A, Rosen N, Solit DB: Genetic predictors of MEK dependence in non-small cell lung cancer. Cancer Res 2008, 68:9375-9383.

20. Rice PL, Barrett BS, Fritz JM, Srebernak MC, Kisley LR, Malkinson AM, DwyerNield LD: Regulation of cytokine-induced prostanoid and nitric oxide synthesis by extracellular signal-regulated kinase $1 / 2$ in lung epithelial cells. Exp Lung Res 2010, 36:558-571.

21. Riely GJ, Kris MG, Rosenbaum D, Marks J, Li A, Chitale DA, Nafa K, Riedel ER, Hsu M, Pao W, Miller VA, Ladanyi M: Frequency and distinctive spectrum of KRAS mutations in never smokers with lung adenocarcinoma. Clin Cancer Res 2008, 14:5731-5734.

22. Fritz JM, Dwyer-Nield LD, Russell BM, Malkinson AM: The Kras mutational spectra of chemically induced lung tumors in different inbred mice mimics the spectra of KRAS mutations in adenocarcinomas in smokers versus nonsmokers. J Thorac Oncol 2010, 5:254-257.

23. Kolch W: Meaningful relationships: the regulation of the Ras/Raf/MEK/ ERK pathway by protein interactions. Biochem J 2000, 351(Pt 2):289-305.

24. Engelman JA, Chen L, Tan X, Crosby K, Guimaraes AR, Upadhyay R, Maira M, McNamara K, Perera SA, Song Y, Chirieac LR, Kaur R, Lightbown A, Simendinger J, Li T, Padera RF, García-Echeverría C, Weissleder R, Mahmood U, Cantley LC, Wong KK: Effective use of PI3K and MEK inhibitors to treat mutant Kras G12D and PIK3CA H1047R murine lung cancers. Nat Med 2008, 14:1351-1356.

25. Johnson L, Mercer K, Greenbaum D, Bronson RT, Crowley D, Tuveson DA, Jacks T: Somatic activation of the K-ras oncogene causes early onset lung cancer in mice. Nature 2001, 410:1111-1116.

26. Pollak M: Insulin and insulin-like growth factor signalling in neoplasia. Nat Rev Cancer 2008, 8:915-928.

27. Dziadziuszko R, Camidge DR, Hirsch FR: The insulin-like growth factor pathway in lung cancer. J Thorac Oncol 2008, 3:815-818.

28. Bitterman PB, Rennard SI, Hunninghake GW, Crystal RG: Human alveolar macrophage growth factor for fibroblasts. Regulation and partial characterization. J Clin Invest 1982, 70:806-822.

29. Rom WN, Basset P, Fells GA, Nukiwa T, Trapnell BC, Crysal RG: Alveolar macrophages release an insulin-like growth factor I-type molecule. J Clin Invest 1988, 82:1685-1693.

30. Olbruck H, Seemayer NH, Voss B, Wilhelm M: Supernatants from quartz dust treated human macrophages stimulate cell proliferation of different human lung cells as well as collagen-synthesis of human diploid lung fibroblasts in vitro. Toxicol Lett 1998, 96-97:85-95.

31. Finkelstein JN, O'Reilly MA, Holm BA, Chess PR, Notter RH: Cell and animal models of lung injury. In Lung injury. Mechanisms, Pathophysiology, and Therapy. Edited by: Notter RH, Finkelstein JN, Holm BA. Philadelphia: Taylor and Francis; 2005:353-404.

32. Zimmermann S, Moelling K: Phosphorylation and regulation of Raf by Akt (protein kinase B). Science 1999, 286:1741-1744.

33. Light $Y$, Paterson H, Marais R: 14-3-3 antagonizes Ras-mediated Raf-1 recruitment to the plasma membrane to maintain signaling fidelity. $\mathrm{Mol}$ Cell Biol 2002, 22:4984-4996.

34. Downward J: Targeting RAS signalling pathways in cancer therapy. Nat Rev Cancer 2003, 3:11-22.

35. Lim KH, Counter CM: Reduction in the requirement of oncogenic Ras signaling to activation of $\mathrm{PI} 3 \mathrm{~K} / \mathrm{AKT}$ pathway during tumor maintenance. Cancer Cell 2005, 8:381-392.

36. David O, Jett J, LeBeau H, Dy G, Hughes J, Friedman M, Brody AR: Phospho-Akt overexpression in non-small cell lung cancer confers significant stage-independent survival disadvantage. Clin Cancer Res 2004, 10:6865-6871. 
37. Mackinnon AC, Farnworth SL, Hodkinson PS, Henderson NC, Atkinson KM, Leffler H, Nilsson UJ, Haslett C, Forbes SJ, Sethi T: Regulation of alternative macrophage activation by galectin-3. J Immunol 2008, 180:2650-2658.

38. Redente EF, Dwyer-Nield LD, Merrick DT, Raina K, Agarwal R, Pao W, Rice PL, Shroyer KR, Malkinson AM: Tumor progression stage and anatomical site regulate tumor-associated macrophage and bone marrow-derived monocyte polarization. Am J Pathol 2010, 176:2972-2985.

39. Wynes MW, Frankel SK, Riches DW: IL-4-induced macrophage-derived IGFI protects myofibroblasts from apoptosis following growth factor withdrawal. J Leukoc Biol 2004, 76:1019-1027.

40. Riely GJ, Marks J, Pao W: KRAS mutations in non-small cell lung cancer. Proc Am Thorac Soc 2009, 6:201-205.

41. Mamay CL, Schauer IE, Rice PL, Dwyer-Nield LD, You M, Sclafani RA, Malkinson AM: Cyclin D1 as a proliferative marker regulating retinoblastoma phosphorylation in mouse lung epithelial cells. Cancer Lett 2001, 168:165-172.

42. Hogg JC, van ES: Pulmonary and systemic response to atmospheric pollution. Respirology 2009, 14:336-346.

43. Sabroe I, Parker LC, Dockrell DH, Davies DE, Dower SK, Whyte MK: Targeting the networks that underpin contiguous immunity in asthma and chronic obstructive pulmonary disease. Am J Respir Crit Care Med 2007, 175:306-311.

44. Enewold L, Mechanic LE, Bowman ED, Zheng YL, Yu Z, Trivers G, Alberg AJ, Harris CC: Serum concentrations of cytokines and lung cancer survival in African Americans and Caucasians. Cancer Epidemiol Biomarkers Prev 2009, 18:215-222.

45. Luo Y, Zhou H, Krueger J, Kaplan C, Lee SH, Dolman C, Markowitz D, Wu W Liu C, Reisfeld RA, Xiang R: Targeting tumor-associated macrophages as a novel strategy against breast cancer. J Clin Invest 2006, 116:2132-2141.

46. Roodman GD: Mechanisms of bone metastasis. N Engl J Med 2004, 350:1655-1664.

47. Raina K, Agarwal R: Combinatorial strategies for cancer eradication by silibinin and cytotoxic agents: efficacy and mechanisms. Acta Pharmaco $\operatorname{Sin} 2007,28: 1466-1475$

48. Buck E, Eyzaguirre A, Rosenfeld-Franklin M, Thomson S, Mulvihill M, Barr S, Brown E, O'Connor M, Yao Y, Pachter J, Miglarese M, Epstein D, Iwata KK, Haley JD, Gibson NW, Ji QS: Feedback mechanisms promote cooperativity for small molecule inhibitors of epidermal and insulin-like growth factor receptors. Cancer Res 2008, 68:8322-8332.

49. Stout RD, Jiang C, Matta B, Tietzel I, Watkins SK, Suttles J: Macrophages sequentially change their functional phenotype in response to changes in microenvironmental influences. J Immunol 2005, 175:342-349.

50. Zerbe LK, Dwyer-Nield LD, Fritz JM, Redente EF, Shroyer RJ, Conklin E, Kane S, Tucker C, Eckhardt SG, Gustafson DL, Iwata KK, Malkinson AM: Inhibition by erlotinib of primary lung adenocarcinoma at an early stage in male mice. Cancer Chemother Pharmacol 2008, 62:605-620.

51. Dwyer-Nield LD, Srebernak MC, Barrett BS, Ahn J, Cosper P, Meyer AM, Kisley LR, Bauer AK, Thompson DC, Malkinson AM: Cytokines differentially regulate the synthesis of prostanoid and nitric oxide mediators in tumorigenic vs. non-tumorigenic mouse lung epithelial cell lines. Carcinogenesis 2005, 26:1196-1206.

52. van der Heijden MS, Bernards R: Inhibition of the PI3K pathway: hope we can believe in? Clin Cancer Res 2010, 16:3094-3099.

53. Frye SV, Johnson GL: Inhibitors paradoxically prime kinases. Nat Chem Biol 2009, 5:448-449.

54. Marais R, Light Y, Paterson HF, Mason CS, Marshall CJ: Differential regulation of Raf-1, A-Raf, and B-Raf by oncogenic ras and tyrosine kinases. J Biol Chem 1997, 272:4378-4383.

55. Malkinson AM, Beer DS: Major effect on susceptibility to urethan-induced pulmonary adenoma by a single gene in BALB/cBy mice. $J$ Natl Cancer Inst 1983, 70:931-936.

56. Chichester CH, Philpot RM, Weir AJ, Buckpitt AR, Plopper CG: Characterization of the cytochrome P-450 monooxygenase system in nonciliated bronchiolar epithelial (Clara) cells isolated from mouse lung. Am J Respir Cell Mol Biol 1991, 4:179-186.

57. Malkinson AM, Dwyer-Nield LD, Rice PL, Dinsdale D: Mouse lung epithelial cell lines-tools for the study of differentiation and the neoplastic phenotype. Toxicology 1997, 123:53-100.

58. Mbawuike IN, Herscowitz HB: MH-S, a murine alveolar macrophage cell line: morphological, cytochemical, and functional characteristics. J Leukoc Biol 1989, 46:119-127.
59. Cumming G, Fidler F, Vaux DL: Error bars in experimental biology. J Cell Biol 2007, 177:7-11.

60. Curran-Everett D: Multiple comparisons: philosophies and illustrations. Am J Physiol Regul Integr Comp Physiol 2000, 279:R1-R8.

61. Curran-Everett D, Benos DJ: Guidelines for reporting statistics in journals published by the American Physiological Society. Am J Physiol Regul Integr Comp Physiol 2004, 287:R247-R249.

doi:10.1186/1476-4598-10-76

Cite this article as: Fritz et al:: Stimulation of neoplastic mouse lung cell proliferation by alveolar macrophage-derived, insulin-like growth factor1 can be blocked by inhibiting MEK and PI3K activation. Molecular Cancer 2011 10:76.

\section{Submit your next manuscript to BioMed Central and take full advantage of:}

- Convenient online submission

- Thorough peer review

- No space constraints or color figure charges

- Immediate publication on acceptance

- Inclusion in PubMed, CAS, Scopus and Google Scholar

- Research which is freely available for redistribution

Submit your manuscript at www.biomedcentral.com/submit
Biomed Central 